\title{
Boredom in Achievement Settings: Exploring Control-Value Antecedents and Performance Outcomes of a Neglected Emotion
}

\author{
Reinhard Pekrun \\ University of Munich
}

Lia M. Daniels

University of Alberta

\author{
Thomas Goetz \\ University of Konstanz and Thurgau University of \\ Teacher Education
}

Robert H. Stupnisky

Laval University

\author{
Raymond P. Perry \\ University of Manitoba
}

\begin{abstract}
The linkages of achievement-related boredom with students' appraisals and performance outcomes were examined in a series of 5 exploratory, cross-sectional, and predictive investigations. Studies 1 and 2 assessed students' boredom in a single achievement episode (i.e., state achievement boredom); Studies 3,4 , and 5 focused on their habitual boredom (i.e., trait achievement boredom). Samples consisted of university students from two different cultural contexts (North America and Germany). In line with hypotheses derived from Pekrun's (2006) control-value theory of achievement emotions, achievementrelated subjective control and value negatively predicted boredom. In turn, boredom related positively to attention problems and negatively to intrinsic motivation, effort, use of elaboration strategies, selfregulation, and subsequent academic performance. Findings were consistent across different constructs (state vs. trait achievement boredom), methodologies (qualitative, cross-sectional, and predictive), and cultural contexts. The research is discussed with regard to the underdeveloped literature on achievement emotions.
\end{abstract}

Keywords: boredom, control-value theory, achievement, achievement emotion, achievement motivation

Boredom is described as one of the plagues of modern society (Klapp, 1986; Spacks, 1995) and is one of the most commonly experienced emotions in many settings today. Yet boredom has received far less attention by researchers than emotions such as anxiety, anger, joy, or interest. In Lewis, Haviland-Jones, and Feldman Barrett's (2008) Handbook of Emotions, boredom is not considered, with the sole exception of a statement that boredom can be reduced by excitement and curiosity (p. 80). Similarly, in

Reinhard Pekrun, Department of Psychology, University of Munich, Munich, Germany; Thomas Goetz, Department of Education, University of Konstanz, Konstanz, Germany, and Thurgau University of Teacher Education, Thurgau, Switzerland; Lia M. Daniels, Department of Educational Psychology, University of Alberta, Edmonton, Alberta, Canada; Robert H. Stupnisky, Department of Education, Laval University, Quebec, Quebec, Canada; Raymond P. Perry, Department of Psychology, University of Manitoba, Winnipeg, Manitoba, Canada.

This research was supported by a TransCoop grant entitled "Academic Risk Factors in College Students" from the German American Academic Council, awarded to Reinhard Pekrun and Raymond P. Perry, and by a grant from the German Research Foundation (Deutsche Forschungsgemeinschaft [DFG]) entitled "Lern-und Prüfungsemotionen" (LearningRelated and Test-Related Emotions) to Reinhard Pekrun.

Correspondence concerning this article should be addressed to Reinhard Pekrun, Department of Psychology, University of Munich, Leopoldstrasse 13, 80802 Munich, Germany. E-mail: pekrun@Imu.de major appraisal theories of emotion, boredom is not listed (Johnstone, Scherer, \& Schorr, 2001). With regard to emotions in achievement settings, test anxiety has been examined in more than 1,000 studies to date (Hembree, 1988; Zeidner, 1998, 2007). In contrast, no more than a handful of studies have explored boredom in school and university contexts (Pekrun, Goetz, Titz, \& Perry, 2002). With the exception of studies on boredom occurring during simple, repetitive tasks at work (Fisher, 1993; Scerbo, 1998), there is a clear lack of research on the boredom experienced when performing achievement-related activities.

One possible reason for this neglect is that boredom is an inconspicuous, "silent" emotion, as compared with manifest affective states like anger or anxiety. From the perspective of teachers, boredom lacks the disruptiveness anger brings to the situation, and from the perspective of clinical practice, it seems to lack psychopathological relevance, in contrast to anxiety. However, boredom may be no less deleterious than other negative emotions. Boredom has been shown to relate to nicotine and alcohol consumption (Amos, Wiltshire, Haw, \& McNeill, 2006; Ho, 1989; Wiesner, Windle, \& Freeman, 2005), drug use (Anshel, 1991; Guinn, 1975), excessive gambling (Blaszcsynski, McConaghy, \& Frankova, 1990), juvenile delinquency (Newberry \& Duncan, 2001), divorce (Gigy \& Kelly, 1992), depression and dissatisfaction with life (Farmer \& Sundberg, 1986), and stress and health problems when coupled with a need to maintain high levels of alertness (Thackray, 
1981). The little evidence available also suggests that boredom can become a severe problem for behavior and performance in achievement settings. Deviant behavior (Wasson, 1981), truancy (Sommer, 1985), and dropout (Bearden, Spencer, \& Moracco, 1989; Tidwell, 1988) of students have been reported to be possible consequences of boredom.

From a theoretical perspective, boredom is of considerable relevance as well. Whereas other emotions are induced by events and objects that are subjectively valued and personally important, boredom is an emotion that is caused by a lack of value in a given situation or activity, as detailed below. This unique feature implies that more comprehensive efforts to explain achievement emotions should take this emotion into account as well.

Given the relevance of the construct from both theoretical and practical perspectives, more research on achievement boredom seems overdue. In the present research, we analyzed the appraisal antecedents and performance consequences of this emotion in a series of five exploratory, cross-sectional, and predictive studies. The studies were organized such that the relationships of boredom with antecedents and outcomes were compared across state and trait constructs of boredom, qualitative and quantitative assessments, and different cultural contexts involving North American and German student samples.

As a framework to derive hypotheses, we used the control-value theory of achievement emotions (Pekrun, 2006; Pekrun, Frenzel, Goetz, \& Perry, 2007). The control-value theory provides an integrative approach for analyzing various emotions experienced in achievement contexts. The theory builds on assumptions from expectancy-value theories of achievement emotions (Pekrun, 1988, 1992b; Turner \& Schallert, 2001), transactional approaches (Folkman \& Lazarus, 1985), attributional theories (Weiner, 1985), and models of the performance effects of emotions (Fredrickson, 2001; Pekrun, 1992c; Pekrun et al., 2002; Zeidner, 1998, 2007). It expands these views by integrating propositions from different theories and by focusing on both outcome-related and activityrelated achievement emotions, including boredom. In the following sections, we first introduce the concept of achievement boredom and summarize previous research, and then present the hypotheses that guided the present studies.

\section{The Construct of Achievement Boredom}

\section{Boredom as an Emotion}

Boredom is commonly seen as an affective state composed of unpleasant feelings, lack of stimulation, and low physiological arousal (Harris, 2000; Mikulas \& Vodanovich, 1993). Symptoms also include prolonged subjective duration of time, implying that "time stands still"; tendencies to escape the situation causing boredom that include behavioral or mental disengagement (e.g., by daydreaming); and slow and monotonous speech (Goetz \& Frenzel, 2006; Johnstone \& Scherer, 2000). This profile of symptoms implies that boredom consists of specific affective components (unpleasant, aversive feelings), cognitive components (altered perceptions of time), physiological components (reduced arousal), expressive components (facial, vocal, and postural expression), and motivational components (motivation to change the activity or to leave the situation). Given this profile, boredom is best regarded as a specific emotion, in line with contemporary component pro- cess definitions of emotions (Kleinginna \& Kleinginna, 1981; Scherer, 2000).

\section{Boredom as an Achievement Emotion}

Achievement emotions are defined as emotions tied to achievement activities or achievement outcomes (Pekrun, 2006). Past research focused on emotions induced by achievement outcomes, such as fear of failure, or pride and shame following performance feedback (Folkman \& Lazarus, 1985; Weiner, 1985; Zeidner, 1998). The definition adopted here posits that emotions arising from achievement-related activities, such as enjoyment and boredom induced by learning activities, are also considered achievement emotions. Two types of achievement emotions differing in object focus can thus be distinguished: activity emotions, pertaining to ongoing achievement-related activities, and outcome emotions, pertaining to the outcomes of these activities (Pekrun et al., 2002; Pekrun, Elliot, \& Maier, 2006).

Along with object focus, valence (positive vs. negative, pleasant vs. unpleasant) and activation (activating vs. deactivating) are two critical dimensions for describing achievement emotions (Pekrun, 2006; Watson \& Tellegen, 1985). Within these dimensions, boredom is categorized as a negative, deactivating emotion, because it is experienced as unpleasant and involves a reduction of physiological activation. Controversy exists as to whether boredom can coincide with increased, rather than reduced, activation of peripheral physiological processes. Whereas a number of studies have reported decreased activation, as indicated by measures of heart rate or skin conductance (Fisher, 1993; see also Goetz \& Frenzel, 2006), some authors have postulated an increase in such activation (Berlyne, 1960; Fenichel, 1934). However, the available evidence suggests that boredom first and foremost reduces activation, even if an increase of activation follows later. Increased activation accompanying prolonged boredom and repetitive activities ("oversaturation"; Karsten, 1928; Lewin, 1928) may result from the investment of mental effort to sustain attention (London, Schubert, \& Washburn, 1972; Scerbo, 1998) or from anger aroused by situational constraints that prevent escape.

\section{Boredom Versus Lack of Interest and Positive Emotions}

Importantly, boredom is not simply equivalent to the absence of interest and positive emotions. Consisting of unique emotional components as outlined earlier, being triggered by specific stimulus conditions (Fisher, 1993), and showing a specific development over time within a given situation (Scerbo, 1998), boredom is more than just a neutral state as defined by a lack of interest or enjoyment. There are many subjective states that are not enjoyable, but would not qualify as boredom (e.g., anger, anxiety). Similarly, given the components described, boredom differs from lack of interest. Lack of interest can be a cause of boredom but is not identical to it. Lack of interest per se is affectively neutral and does not cause emotional pain, in contrast to the "torments of boredom" (Berlyne, 1960, p. 192). Due to differences in affective load, lack of interest and enjoyment, on the one hand, and boredom, on the other, also have different motivational consequences (Goetz \& Frenzel, 2006). Whereas lack of interest and enjoyment implies neither the wish to engage in an activity nor the wish to avoid it, 
boredom triggers impulses to escape the situation. Lack of interest and enjoyment entail a lack of approach motivation, whereas boredom promotes avoidance motivation. By implication, as seen from a motivational perspective, the difference between these constructs is conceptually equivalent to the difference between a lack of approach and the presence of avoidance.'

\section{Previous Research on Boredom in Achievement Settings}

Research on student engagement has focused on achievement goals, interest, and intrinsic motivation (Elliot \& Dweck, 2005; Harackiewicz, Durik, Barron, Linnenbrink-Garcia, \& Tauer, 2008; Hulleman, Durik, Schweigert, \& Harackiewicz, 2008; Hidi, 2006; Pekrun, Elliot, \& Maier, 2009; Sansone \& Thoman, 2005). In contrast, studies on the boredom experienced in achievement settings are largely lacking. The few studies available addressed the relationships of boredom with ability, lack of stimulation and value, and effort invested in task performance. Most of the studies used survey and interview methodology, with the exception of experimental studies on boredom induced by repetitive tasks (Fisher, 1993).

\section{Ability and Perceived Control as Antecedents of Boredom}

Traditionally, boredom was assumed to be caused by a lack of challenge, as resulting from a combination of high ability and low task demands (Csikszentmihalyi, 1975). In the educational literature, boredom was attributed to gifted children dealing with environments tailored to the needs of average-ability students ("The Bored and Disinterested Gifted Child"; Rennert \& Berger, 1956; Sisk, 1988). In contrast, the evidence from survey studies suggests that boredom is more frequently experienced by low-ability than by gifted individuals. Roseman (1975) found that bored students were overrepresented among middle-school students having IQ scores of less than 95 and that boredom correlated negatively with teacher ratings of students' academic ability. Similarly, Fogelman (1976) showed that 11-year-olds who reported being "often bored" in their spare time had significantly lower verbal and nonverbal cognitive abilities, as well as lower academic performance in reading and arithmetic, than students who were "sometimes bored" or "always enjoyed" their leisure time.

Bored students also report lower perceived control and lower academic self-concepts. In a study of 12- to 16-year-old students at risk of academic failure, Dicintio and Gee (1999) found that subjective control over learning activities correlated negatively with boredom arising from these activities. Similarly, in a study of middle-school students' emotions in language classes, students' self-concept of ability and boredom correlated negatively (Goetz, Pekrun, Hall, \& Haag, 2006). Internal locus of control and successful "boredom coping," on the other hand, correlated positively in a study with college students (Hamilton, Haier, \& Buchsbaum, 1984). In sum, the little evidence available suggests that high competencies and perceived control can protect against boredom rather than making individuals susceptible to experiencing this emotion.

\section{Lack of Stimulation and Value as Antecedents of Boredom}

Monotonous, repetitive tasks lacking complexity, variety, and cognitive stimulation are thought to induce boredom. Empirical evidence from work-related studies corroborates this assumption (Fisher, 1993). For example, Scerbo (1998) found that monotonous vigilance tasks induced boredom, with the maximum intensity of boredom reached no later than 10 to $15 \mathrm{~min}$ into task engagement. Similarly, Coury and Drury (1986) reported that a product quality monitoring task induced increasing boredom. As for educational settings, Roseman's (1975) study found that the number of school subjects perceived as boring related to students' claims that school "was the same day after day." In addition, the results of a few studies suggest that approach achievement motives and mastery achievement goals relate negatively to students' boredom. In the study by Gjesme (1977), sixth graders with a high motive to strive for success reported less boredom than students having high fearof-failure scores. Mastery goals related negatively to boredom in undergraduate students' academic activities (Jagacinski \& Duda, 2001; Pekrun, Elliot, \& Maier, 2006; 2009) and in elementary students' sports activities (Duda, Fox, Biddle, \& Armstrong, 1992). Similarly, Goetz et al. (2006) found that students' subjective values of academic achievement correlated negatively with their reported boredom.

\section{Effects of Boredom on Achievement Behavior}

The findings of a few interview and survey studies suggest that boredom relates negatively to attention and effort at achievement activities. Using interviews with sixth- and seventh-grade students, Jarvis and Seifert (2002) found that students withdrew effort at school as a result of experiencing boredom. Farmer and Sundberg (1986) reported that undergraduates' boredom proneness correlated negatively with their attentiveness during lectures. In Watt and Vodanovich's (1999) study, college students' boredom related negatively to their educational involvement and career planning. Similarly, in Roseman's (1975) investigation, students' boredom related negatively to teacher ratings of how hard students worked and to parents' ratings of effort invested in homework. Consistent with these findings, successful coping with boredom related negatively to college students" "wish to be elsewhere" and effort

\footnotetext{
' From a motivational perspective, being interested in an activity and enjoying it implies positive intrinsic value (Eccles, 2005), thereby inducing positive intrinsic motivation to perform the activity (approach intrinsic motivation). Lack of interest and enjoyment indicates a lack of positive intrinsic value, implying that positive intrinsic motivation is lacking and that extrinsic motivation is necessary to sustain engagement (Sansone \& Thoman, 2005). In contrast, boredom involves more than just a lack of positive intrinsic value and motivation. Boredom implies that the activity acquires negative intrinsic value, thus inducing motivation to avoid engagement (avoidance intrinsic motivation, or negative intrinsic motivation; Pekrun, 1993). By implication, lack of interest per se should leave the motivation to perform an activity unaffected (other things being equal). In contrast, by promoting avoidance motivation, boredom reduces the overall motivation to perform an activity. Thus, the difference between lack of interest and boredom is conceptually equivalent to the difference between lack of approach motivation, on the one hand, and the presence of avoidance motivation, on the other.
} 
needed to concentrate, and related positively to the quality of concentration (Hamilton et al., 1984).

\section{Effects of Boredom on Performance}

Experimental studies have demonstrated that boredom arising from performing monotonous tasks, such as vigilance or data entry tasks, reduces task performance and increases performance variability over time (e.g., Cantor, 1968; Hamilton et al., 1984; Kass, Vodanovich, Stanny, \& Taylor, 2001; Pan, Shell, \& Schleifer, 1994; Sawin \& Scerbo, 1995). In line with this evidence, Wallace, Vodanovich, and Restino (2003) found positive relations between boredom proneness and self-reported everyday cognitive failures involving memory lapses and attentional distractibility in samples of undergraduate students and military personnel.

However, there is a conspicuous lack of studies on boredom and performance involving more complex tasks, and on boredom and academic performance. Exceptions consist of a few studies that produced conflicting results. Larson and Richards (1991) found a weak, positive association between upper elementary students' grade point average (GPA) and boredom during school hours. In contrast, Goetz, Frenzel, Pekrun, Hall, and Lüdtke (2007) reported negative correlations for eighth and eleventh graders' boredom and achievement in different school subjects, and Maroldo (1986) reported a negative correlation between college students' boredom and their GPA. Similarly, Daniels et al. (2009) and Pekrun et al. (2009) found that boredom experienced by undergraduate students in university courses related negatively to their performance in the courses, suggesting that boredom can negatively affect students' academic achievement.

In sum, the meager evidence available suggests that low ability and lack of achievement values relate to the boredom experienced by students. In addition, the findings imply that boredom relates to reduced attention, effort, and performance in achievement settings. However, the available evidence is too limited to warrant more general conclusions, indicating a clear need for more research on students' boredom. Furthermore, most of the extant research consists of survey and interview studies that were exploratory in nature, rather than being guided by theory. Typically, these studies employed one-item measures of boredom with unknown psychometric properties (e.g., Fogelman, 1976; Gjesme, 1977; Larson \& Richards, 1991), relied on qualitative interview data only, or used general boredom scales not specifically assessing boredom in achievement settings. There is a lack of theory-based research systematically examining the antecedents and performance consequences of achievement-related boredom, especially in terms of studies that target students' boredom in demanding academic environments, use direct measures of achievement boredom, and employ longitudinal designs in addition to cross-sectional survey methodology.

\section{Theoretical Framework: A Control-Value Model of Achievement Boredom}

The five studies presented herein are based on hypotheses derived from the control-value theory of achievement emotions (Pekrun, 2000, 2006; Pekrun et al., 2007; Pekrun et al., 2002). These hypotheses address control and value appraisals as anteced- ents of boredom as well as the effects of boredom on achievement behavior and performance.

\section{Control and Value Appraisals as Antecedents of Boredom}

The control-value theory posits that appraisals of ongoing achievement activities, and of their past and future outcomes, are of primary relevance for the instigation of achievement emotions. More specifically, the theory stipulates that individuals experience distinct achievement emotions when they perceive being in or out of control of achievement activities and outcomes that are subjectively important to them. This proposition implies that subjective control and subjective value are the proximal determinants of these emotions. The term subjective control refers to the perceived causal influence of an agent over actions and outcomes (Skinner, 1996), and the term subjective value refers to the perceived valences of actions and outcomes. For example, it is expected that enjoyment of learning is instigated when a student experiences a sense of control over learning and values the material, and that anxiety before an exam is aroused when performance on the exam is perceived as not sufficiently controllable and the outcome of the exam as important.

With regard to boredom, however, the theory posits that this emotion differs from other achievement emotions by being aroused when achievement-related activities are perceived as lacking value, rather than being subjectively important. The theory proposes a negative relationship between the subjective value of activities in a given achievement setting, on the one hand, and the frequency and intensity of boredom experienced in this setting, on the other. ${ }^{2}$ More specifically, it is expected that a lack of intrinsic values of achievement activities, rather than a lack of extrinsic, instrumental utility, is critical for the instigation of boredom. For example, if a student doing assignments for a course perceives the course material as uninteresting and mastery of the material as being of little relevance for personal identity, he or she is assumed to experience boredom when studying for the course.

Furthermore, boredom is also posited to be influenced by subjective control. In Csikszentmihalyi's (1975) conception, boredom is assumed to be induced when individual capabilities are high relative to task demands, suggesting that boredom is experienced when control is high. In contrast, the control-value theory posits a curvilinear relationship between control and boredom, with more boredom being experienced under conditions of high or low control, as compared with moderate control. Thus, it is expected that boredom may also occur when there is a lack of control over the activity because demands exceed individual capabilities (see Acee et al., 2010, for a similar view).

\footnotetext{
${ }^{2}$ Lack of value of activities in a given achievement setting differentiates achievement-related boredom from achievement-related hopelessness and from depression. The difference between boredom and hopelessness is that hopelessness relates to the nonattainability of valued outcomes, whereas boredom is caused by a lack of value. The difference between boredom and depression is that boredom relates to a lack of value of the current activity but does not undermine the attractiveness of alternative activities, whereas depression implies that there is no longer any subjective value in any activity whatsoever.
} 
For any given setting, the context and the type of activities under consideration likely determine whether boredom is produced by low or high control. In most academic contexts, tasks are complex and present challenges that must be overcome if success is to be attained. For these settings, it is unlikely that task demands and individual capabilities jointly create a situation in which perceptions of control are sufficiently high to induce feelings of boredom. Rather, it seems that, in relation to task demands, individuals are more likely to experience low or moderate control, resulting in a negative relationship between observable levels of control, on the one hand, and boredom, on the other. Therefore, in the present research focusing on boredom in demanding achievement settings, we expected to find negative effects of control on boredom, rather than curvilinear relationships.

\section{Effects of Boredom on Achievement Behavior and Performance}

The control-value theory (Pekrun, 2006) considered here posits that the effects of emotions on performance are mediated by three distinct types of functional mechanisms: the availability of cognitive resources, the motivation underlying achievement activities, and the strategies used when performing these activities, including the self-regulation of these activities. Emotion effects on performance are expected to be a joint function of these mechanisms. For boredom, the following is proposed.

Cognitive resources. Boredom functions to withdraw attention from activities lacking value and to direct attention toward more rewarding stimuli and activities. By implication, it is expected that boredom experienced during an achievement task reduces cognitive resources available for the task by causing attention problems. Boredom is posited to reduce task-related attention, increase distractibility, and induce task-irrelevant thinking focused on alternative contents.

Motivation. Boredom is expected to reduce the motivation to perform achievement activities. More specifically, as argued earlier, boredom caused by an activity is aversive and induces motivation to avoid the activity. Being aversive and avoidanceoriented, boredom is incompatible with experiencing situational interest and enjoyment in the activity. Therefore, it is expected to impair intrinsic motivation to engage in the activity. Furthermore, on account of its negative effects on motivation, boredom is also expected to reduce the effort invested in the activity.

Strategies and self-regulation. In contrast to activating emotions, which are thought to facilitate the use of cognitive strategies, boredom is posited to lead to a shallow processing of information and to reduce the use of any task-related cognitive and metacognitive strategies. Boredom is thus expected to reduce both flexible strategies, such as elaboration of learning material, and more rigid strategies, such as rehearsal of material. Similarly, by encouraging a passive approach to learning, boredom is expected to reduce the self-regulation of achievement activities as defined by active goal setting, strategy selection, and monitoring of outcomes.

Performance. As a consequence of the negative effects of boredom on attention, motivation, and strategy use, boredom is expected to exert uniformly negative performance effects on both simple and more complex tasks, in contrast to activating negative emotions, such as anxiety, which have more variable effects
(Pekrun, 2006; Zeidner, 1998). By implication, boredom is posited to exert negative effects on overall academic achievement.

\section{Summary of Aims and Hypotheses}

In five studies, we tested the proposed links between boredom and related antecedents and effects in samples of German (Studies 1, 2, and 3) and North American (Studies 4 and 5) undergraduates. In testing our hypotheses, we designed the studies to address relationships of students' boredom with control and value appraisals, as well as attention problems, intrinsic motivation, effort, use of elaboration and rehearsal strategies, self-regulation of learning, and academic performance. Study 1 used a semistructured, qualitative questionnaire to explore boredom within single episodes of learning at university (state achievement boredom). In Study 2, quantitative measures were used to assess state achievement boredom during learning episodes. Studies 3 and 4 considered boredom as habitually experienced in achievement settings (trait achievement boredom). By using similar measures, Studies 3 and 4 provided a comparison of relationships across German (Study 3) and North American (Study 4) student samples. Finally, Study 5 employed a longitudinal design to determine whether control and value predicted boredom, and whether boredom predicted achievement, in an introductory psychology course over one academic year.

The research strategy implied by this sequence of studies involved testing the generalizability of findings across state and trait constructs of boredom (Studies 1 and 2 vs. Studies 3 to 5) and across qualitative and quantitative methods of assessing boredom (Study 1 vs. Studies 2 to 5). Furthermore, by using both German and North American student samples, we sought to test generalizability across different cultural contexts. Traditionally, the German and North American university systems have differed in a number of aspects that have important implications for students' emotions. Specifically, although German universities are currently undergoing change, many study programs are still less structured in the German system than in the North American system, implying that more self-regulation is expected from students in these programs. Second, achievement demands and assessments are organized differently. There is less frequent high-stakes testing in the German system to date, and course exams are typically less frequent. Both of these differences were true for the German and North American samples in the present research.

Succinctly stated, the primary hypotheses examined in our research were as follows:

Hypothesis 1: Subjective control and value relating to achievement activities negatively predict boredom.

Hypothesis 2: Boredom relates positively to attention problems and negatively to intrinsic motivation, effort, elaboration, rehearsal, and self-regulation of learning.

Hypothesis 3: Boredom negatively predicts academic performance.

\section{Study 1}

Study 1 provided descriptive information on the relations between control-value appraisals, boredom, and learning by using 
open-ended questionnaires to explore students' emotions experienced in a university setting. A subsidiary aim was to validate our proposition that achievement boredom should be categorized as a negative deactivating emotion. The study focused on state achievement boredom experienced within single achievement-related episodes.

\section{Method}

Participants and procedure. A total of 323 undergraduates (226 female and 97 male; mean age $=23.46$ years, $S D=3.26$ ) enrolled in psychology or education courses at a German university participated in the study. Participants completed a semistructured questionnaire immediately after having attended a class or having studied material related to class. In Part I, participants answered questions on the emotions they had experienced when attending class or studying. In Part II, they described one of their reported emotions in more detail. The experimenter selected this target emotion at random from all of the emotions presented by the student. A subsample of 29 students (19 female, 10 male) were asked to provide descriptions of boredom.

\section{Questionnaire and Data Analysis}

Frequency and intensity of boredom. In Part I, participants indicated, for each of 17 different preselected emotions, including boredom, whether they had experienced the emotion in the preceding situation, and rated the intensity of the emotion on a scale ranging from 1 (weak) to 5 (strong).

Components and correlates of boredom. In Part II, the 29 participants selected to elaborate on boredom were asked to provide open-ended descriptions answering six questions. Three questions related to the components of boredom, including (a) affective feelings ("When you experienced this emotion, what exactly did you feel? Please describe these feelings, using your own words"); (b) physiological changes ("When you experienced this feeling, did you notice any bodily changes? If yes, please describe"); and (c) emotional expression ("When you experienced this feeling, did you notice any changes in your facial expression, postural expression, body movements, or speech? If yes, please describe"). Three questions targeted correlates of the emotion, including (d) cognitions ("Which thoughts did you have when experiencing this feeling?"); (e) motivational reactions ("What did the feeling motivate you to do, what would you have liked to do?"); and (f) behavior and performance outcomes ("How did this emotion affect your learning and performance?"). To code answers, we used classification systems developed by Pekrun (1992a) and Titz (2001). Interrater reliabilities were $88 \%, 94 \%, 89 \%, 80 \%, 83 \%$, and $92 \%$, respectively, for answers to the six questions.

\section{Results and Discussion}

Preliminary analyses.

Frequency and intensity of achievement-related boredom. For the entire sample $(N=323)$, boredom was experienced in $42.2 \%$ of all situations described (Table 1) and was reported significantly more frequently than anxiety $(28.0 \%)$, anger (19.3\%), or hopelessness (13.6\%), although less frequently than enjoyment $(66.5 \%)$. The average reported intensity of boredom $(M=2.41$,
$S D=1.16)$ was lower than the mean intensity of all emotions assessed $(M=2.80, S D=1.12)$. Thus, boredom was an emotion experienced with relatively low average intensity but rather high frequency when attending class or studying.

Components of the boredom experience: Boredom as an unpleasant, physiologically deactivating emotion. In response to Question 1 on affective components, all but one of the descriptions indicated that boredom was unpleasurable, thus corroborating the classification of achievement boredom as a negative (unpleasant) emotion. ${ }^{3}$ The boredom experienced was described as relating to dissatisfaction, feelings of emptiness, an aversive lack of goals, and an unpleasant perception of time as being excessively prolonged, in line with previous reports on boredom (Harris, 2000; Mikulas \& Vodanovich, 1993).

Descriptions of physiological changes and emotional expression were analyzed for peripheral physiological and motor responses indicating activation versus deactivation. Of the 23 responses pertaining to activation versus deactivation, 19 indicated deactivation by symptoms such as sleepiness and yawning, slack body posture, cold hands, and an empty gaze. Four descriptions indicated activation (e.g., increases in heart rate and respiration rate). Activation in these cases likely was due to factors other than boredom, including activating emotions that occurred simultaneously with boredom, environmental factors, and motivational ambivalence. ${ }^{4}$ Although we cannot rule out the possibility that boredom may produce physiological activation under certain conditions, the overall pattern of results supports the proposition that boredom is a deactivating emotion, in contrast to theoretical positions (e.g., Fenichel, 1934) that speculate this emotion to be physiologically activating.

Control and value appraisals. Of the 18 reports describing control-related cognitions, 14 indicated that one's own competence and attainment were judged as low or that task demands were judged as high. In contrast, only four of the reports implied high perceived competence or low demands. These findings corroborate that boredom in demanding achievement settings can be related to high-competence/low-demand conditions which imply high sub-

\footnotetext{
${ }^{3}$ The exception was one student indicating that his or her boredom experienced while studying "is a feeling that I really can enjoy."

${ }^{4}$ In the first case, boredom was coupled with activating nervousness caused by an upcoming exam. In the second case, boredom experienced while listening to a monotonous presentation led to anger, which may have produced the increase of heart rate and respiration rate described by the student. The third report indicated that it was hot during the lecture the student attended, which may explain why the student reported having been sleepy while at the same time experiencing motoric restlessness. In the fourth case, the reported combination of slack body posture and muscular tension may have been due to lack of intrinsic value of the repetitive learning task at hand, combined with thoughts about the instrumental importance of mastering the task, likely implying a conflict between deactivating boredom and activating instrumental motivation. An additional analysis of the co-occurrence of boredom with other emotions as reported in Part I of the questionnaire corroborated that boredom can be experienced in situations in which other affective states are experienced as well. Emotions reported as having being experienced frequently in the same situation as boredom included disappointment, hopelessness, sadness, envy, anger, and anxiety. However, this finding should be interpreted cautiously, as boredom and other emotions may have been experienced sequentially, rather than simultaneously, within the relevant situation.
} 
Table 1

Summary of Main Findings for Study 1

\begin{tabular}{llc}
\hline \multicolumn{1}{c}{ Variable } & \multicolumn{1}{c}{ Predominant attribute for boredom } & $\begin{array}{c}\text { Percentage of } \\
\text { boredom reports }\end{array}$ \\
\hline Frequency & $\begin{array}{l}\text { Most frequently reported negative emotion, experienced } \\
\text { in 42.2\% of academic situations }\end{array}$ & \\
Pleasantness & Unpleasant feelings & 96.5 \\
Activation & Physiological deactivation & 82.6 \\
Control & Perceived competence low, task demands high & 77.7 \\
Value & Subjective value of studying low & 90.0 \\
Attention & Lack of concentration, distractibility, task-irrelevant & 100.0 \\
Motivation & thinking & 92.3 \\
Perceived performance & Reduced motivation to learn, motivation to perform & 89.4 \\
\hline
\end{tabular}

${ }^{a}$ Content dimensions used to describe attributes of boredom.

jective control, but is more typically related to low-competence/ high-demand conditions which imply low subjective control. Furthermore, 18 out of 24 reports referring to value cognitions indicated that the perceived value of attending class or studying was low or questionable. Reasons given were lack of interest in learning material, doubts about being enrolled in a course meeting personal goals, and lack of instrumental value for obtaining a job after graduating from university. Two of the reports indicated that studying was seen as instrumentally useful, but boring because of lack of intrinsic value, thus implying motivational ambiguity. Overall, these results corroborate that a perceived lack of value regarding achievement activities coincides with students' experiences of boredom.

\section{Achievement behavior and performance outcomes}

Attention problems. All of the 26 reports addressing taskrelated attention indicated that attention was reduced, as indicated by lack of concentration, distractibility, and task-irrelevant thinking (e.g., daydreaming). Those who described the dynamics of concentration indicated that concentration decreased over time. Task-irrelevant thinking was related to positive events and actions outside achievement settings (e.g., going biking, meeting friends, having dinner) in 24 of the 26 reports, indicating complete disconnectedness between current task contents and irrelevant thoughts. This contrasts with the irrelevant thoughts centering on achievement-related concerns that are typical for test anxiety (Zeidner, 1998). Overall, these findings uniformly confirm that boredom coincides with attention problems.

Motivation. Of the 26 reports addressing motivational reactions, 24 indicated that boredom reduced motivation to learn, including (a) motivation to leave class, stop learning, or postpone it (41\% of the relevant reports); (b) motivation to do something else instead of studying (66\%); (c) lack of intrinsic motivation to learn due to boredom (20\%); and (d) lack of any motivation whatsoever (8\%). Similar to the contents of irrelevant thinking, motivation to do something else related to pleasurable nonacademic activities in all descriptions. These findings are in line with the hypothesis that boredom reduces intrinsic and overall motivation to learn. ${ }^{5}$

Perceived performance. In 17 out of 19 responses to Question 6 concerning performance consequences, respondents indicated that boredom had impaired the quality of study behavior and performance. In two cases, students reported that boredom reduced task-related attention, but that a decrease of performance was prevented by trying to cope with boredom in terms of exerting self-discipline (first case) or actively engaging in course discussions (second case). Performance decrements produced by boredom were attributed to (a) disengagement from learning by engaging in task-irrelevant behavior while in class or studying, such as talking to neighbors, drawing figures, or watching other students (mentioned in 58\% of the relevant reports); (b) reduced quality of performance due to lack of concentration (29\%); and (c) escaping from the causes of boredom by leaving class (5\%). Two respondents also mentioned effects of boredom on the quality of information processing. Both indicated that boredom induced a superficial approach to processing learning material, including a lack of differentiation between focal and less important aspects of information.

\section{Conclusions}

The findings of this study show that achievement boredom can be classified as an unpleasant, deactivating emotion, similar to boredom described for other settings (Ragheb \& Merydith, 2001). Furthermore, the results suggest that boredom can relate to both high-control and low-control conditions, but was more frequently reported in relation to low-control conditions, in line with Hypothesis 1. In addition, results corroborate that boredom relates to reduced subjective values of achievement activities. Finally, findings confirm that boredom is described as causing attention prob-

\footnotetext{
${ }^{5}$ Two reports diverged from findings on reduced motivation. In one report, the respondent was studying material for an exam, hoped for success on the exam, experienced time pressure, and wanted to cope with boredom by increasing his or her effort to focus attention on the learning material. In the second case, the respondent had to prepare for an important exam by reading uninteresting textbooks and reported on motivation to search for alternative, more interesting material. In both cases, the motivation on which the respondent reported aimed at coping with boredom in order to ensure successful preparation. Overall, the findings imply that boredom can induce motivation to cope by increasing effort or changing strategies, but that it typically leads to a loss of motivation for task-related engagement.
} 
lems and adversely affecting motivational engagement and performance while studying, in line with Hypotheses 2 and 3. The generalizability of these findings, however, is clearly limited by the small size of the boredom sample $(n=29)$ and the subjective nature of students' qualitative descriptions of emotional episodes.

\section{Study 2}

In Study 2, we used quantitative measures to explore the relationships of state achievement boredom with appraisals and learning. The study included all of the appraisal antecedents and outcomes of boredom addressed by our original hypotheses (i.e., control, value, attention problems, intrinsic motivation, effort, elaboration, rehearsal, self-regulation, and performance). By assessing boredom in the context of single achievement-related episodes, Study 2 focused on achievement boredom as a temporary state, as did Study 1. In combination with Study 1, a primary purpose was to investigate whether relationships for state achievement boredom were consistent across qualitative and quantitative measures of boredom.

\section{Method}

Participants and procedure. A total of 203 students (100 female and 103 male; mean age $=24.00$ years, $S D=3.47$ ) enrolled in undergraduate courses at a German university participated in Study 2. Participants were approached while absorbed with learning material in study rooms that are part of the university's library, and completed the study measures individually in one session in that room.

\section{Measures}

Boredom. The state version of the Learning-Related Boredom scale of the Achievement Emotions Questionnaire (AEQ; Pekrun et al., 2002; Pekrun, Goetz, \& Perry, 2005) was used to assess participants' boredom while studying. The instructions for the measure asked respondents to describe how they currently felt when studying (eight items; e.g., "Today, studying for my courses bores me"; "The material bores me to death"). Participants responded on a scale ranging from 1 (strongly disagree) to 5 (strongly agree), and the scores were summed to form the boredom index $(\alpha=.89)$.

Control and value. A five-item scale related to influencing academic achievement (Schwarzer, 1986) was used to measure achievement-related subjective control (e.g., "I know exactly what to do to get good grades"; "When preparing adequately, I'm always successful in getting good grades"). The state version of the four-item Academic Value Scale was used to assess the subjective value of the current achievement activity (Titz, 2001; e.g., "The material I deal with today is of great personal relevance for me"; "What I'm doing at present is not one of my favorite activities" [reverse scored]; items were adapted from the Study Interest Questionnaire [SIQ]; Schiefele, Krapp, Wild, \& Winteler, 1993). Participants responded on a scale ranging from 1 (strongly disagree) to 5 (strongly agree), and the scores were summed to form the control and value indexes $(\alpha=.78$ and .80 for control and value, respectively).

Attention problems, intrinsic motivation, effort, elaboration, rehearsal, and self-regulated learning. Attention problems were assessed with a state version of the Attention Problems scale of
Wild and Schiefele's (1994) Learning Strategies Questionnaire. This instrument is a modified German version of the Motivated Strategies for Learning Questionnaire (Pintrich, Smith, Garcia, \& McKeachie, 1991). The six items of the attention problems scale refer to lack of concentration (e.g., "I lack concentration"), distractibility ("I am easily distractible"), and task-irrelevant thinking ("I notice that my thoughts are elsewhere"). Instructions asked participants to indicate how they felt, at present, when studying $(1=$ strongly disagree, $5=$ strongly agree $; \alpha=.92)$. Intrinsic motivation was measured with a three-item Intrinsic Motivation Scale (Titz, 2001). This scale assesses motivation based on enjoyment of, and interest in, studying academic material (e.g., "At present, I am motivated to study because I am interested in the material"; $1=$ strongly disagree, $5=$ strongly agree $; \alpha=.88$ ).

Effort, elaboration, and rehearsal were measured with state versions of scales of the Learning Strategies Questionnaire (Wild \& Schiefele, 1994). Instructions asked respondents how they currently dealt with learning material. The scales consisted of five items for effort (e.g., "I invest much effort today while studying"), six items for elaboration (e.g., "I try to relate the material to what I already know"), and four items for rehearsal (e.g., "I read the material over and over again"). Participants responded by using a scale ranging from 1 (strongly disagree) to 5 (strongly agree), and the scores were summed to form the effort, elaboration, and rehearsal indexes $(\alpha=.71, .75$, and .73 , respectively). Selfregulated learning was measured with a state version of the sixitem Perceived Self-Regulation at Learning Scale (Titz, 2001), which assesses students' current self-regulation of learning goals, use of learning strategies, and monitoring of learning outcomes (e.g., "I set my own goals today that I want to attain when studying"; "When studying today, I decide for myself which strategies to use"; "I am able to evaluate for myself how I make progress at learning today"; 1 = strongly disagree, 5 = strongly agree; $\alpha=.61)$.

Perceived performance. A four-item self-report scale (Titz, 2001) was used to assess students' perceived current performance at learning (e.g., "I am successful in making progress at learning today"; 1 = strongly disagree, $5=$ strongly agree $; \alpha=.91$ ).

\section{Results and Discussion}

Preliminary analysis. Table 2 presents the descriptive statistics for each of the variables. We also analyzed descriptive statistics separately for female and male students. There were significant gender differences in academic control $(M \mathrm{~s}=14.21$ and $15.73, S D s=4.21$ and 3.39 , for female and male students, respectively), $t(201)=-2.80, p<.01$, and elaboration $(M \mathrm{~s}=18.58$ and $16.85, S D \mathrm{~s}=4.69$ and 4.41$), t(201)=2.27, p<.05$, indicating that female students reported less control and more elaboration than male students. However, effect sizes for these differences were small $(d \mathrm{~s}=-.28$ and .27 for control and elaboration, respectively; Cohen, 1988). Gender differences were not significant for any of the other study variables.

Relationships of control and value with boredom. We analyzed relationships between the study variables by Pearson product-moment correlations (Table 2). In line with Hypothesis 1, academic control was negatively correlated with boredom while studying. Similarly, the subjective value of studying correlated negatively with boredom. These findings are consistent with the 
Table 2

Pearson Product-Moment Correlations and Descriptive Statistics for Study 2

\begin{tabular}{|c|c|c|c|c|c|c|c|c|c|c|}
\hline Variable & 1 & 2 & 3 & 4 & 5 & 6 & 7 & 8 & 9 & 10 \\
\hline 1. Boredom & - & & & & & & & & & \\
\hline 2. Control & $-.24^{* *}$ & - & & & & & & & & \\
\hline 3. Value & $-.70^{*+*}$ & $.32^{* * *}$ & - & & & & & & & \\
\hline 4. Attention problems & $.65^{* *}$ & $-.28^{* *}$ & $-.51^{* * *}$ & - & & & & & & \\
\hline 5. Intrinsic motivation & $-.61^{* *}$ & $.34^{* *}$ & $.79^{* * *}$ & $-.47^{* *}$ & - & & & & & \\
\hline 6. Effort & $-.45^{* * *}$ & $.22^{* *}$ & $.30^{* * *}$ & $-.56^{* * *}$ & $.27^{* *}$ & - & & & & \\
\hline 7. Elaboration & -.07 & .09 & .06 & -.11 & .13 & .03 & - & & & \\
\hline 8. Rehearsal & $.19^{*}$ & -.15 & -.13 & $.25^{* * *}$ & -.10 & -.03 & .05 & - & & \\
\hline 9. Self-regulation & $-.26^{* *}$ & $.30^{* *}$ & $.30^{* * *}$ & $-.33^{* * \cdots}$ & $.31^{* *}$ & $.36^{* *}$ & .13 & -.06 & - & \\
\hline 10. Perceived performance & $-.26^{* *}$ & $.55^{* *}$ & $.33^{4+4}$ & $-.26^{\text {twin}}$ & $.40^{*}$ & $.19^{* *}$ & .00 & .07 & $.26^{*+*}$ & - \\
\hline$M$ & 17.15 & 14.98 & 16.34 & 15.51 & 8.85 & 18.05 & 17.61 & 18.56 & 20.86 & 9.84 \\
\hline$S D$ & 6.49 & 3.89 & 4.40 & 5.14 & 3.02 & 3.44 & 4.50 & 5.05 & 3.52 & 2.72 \\
\hline Possible range & $8-40$ & $5-25$ & $5-25$ & $6-30$ & $3-15$ & $5-25$ & $6-30$ & $7-35$ & $6-30$ & $4-20$ \\
\hline Observed range & $8-38$ & $5-24$ & $5-25$ & $6-30$ & $3-15$ & $10-25$ & $7-30$ & $7-30$ & $10-30$ & $4-16$ \\
\hline
\end{tabular}

${ }^{*} p<.05 . \quad \stackrel{\text { n** }}{*} p<.01$

results of Study 1, and with the hypothesis that lack of control and lack of value serve as antecedents to students' boredom in academic achievement settings.

The propositions of the control-value theory imply that relationships between control and boredom can take curvilinear forms. For academic settings, however, we expected that controlboredom relationships would be negatively linear because of the high demands implied by these settings. In order to test for linearity, we performed a simultaneous multiple regression analysis including linear and quadratic terms for control. The quadratic term was computed after centering the variables. Control had a significant linear effect on boredom $(\beta=-.32, p<.001)$. There was no significant effect for the quadratic term. This finding indicates that the relationship between control and boredom takes linear rather than quadratic forms, in line with our earlier reasoning.

Relationships of boredom with achievement behavior and perceived performance. Boredom correlated positively with attention problems during learning activities (Table 2), in line with the hypothesis that boredom leads to lack of concentration, distractibility, and task-irrelevant thinking. Furthermore, boredom correlated negatively with intrinsic motivation to learn, self-reported effort at learning, and the perceived selfregulation of learning. Contrary to expectations, however, boredom did not correlate significantly with elaboration and had a small positive correlation with rehearsal. An explanation for the positive relationship with rehearsal may be effects of rehearsal on boredom, rather than effects of boredom on the use of rehearsal. It seems likely that rehearsing material to be learned can be experienced as repetitive and monotonous, thus implying a lack of cognitive stimulation that can induce boredom.

This pattern of relationships is consistent with the findings of Study 1, and with Hypothesis 2 that boredom is detrimental to students' attention, motivation, investment of effort, and selfregulation at learning. Finally, boredom also correlated negatively with students' perceived performance in terms of estimated current progress at learning, in line with Hypothesis 3 that boredom impairs performance at academic tasks.

\section{Conclusions}

The findings of Study 2 were consistent with those of Study 1 , thus corroborating that relationships of boredom with achievement behavior and perceived performance are structurally equivalent across qualitative and quantitative approaches. Across the two studies and in line with our hypotheses, control and value related negatively to boredom, and boredom related negatively to attention, intrinsic motivation, effort, self-regulation of learning, and performance. Contrary to expectations, however, boredom did not relate significantly to elaboration and correlated positively with rehearsal. The positive relationship with rehearsal may have been due to effects of rehearsal on boredom, rather than to reverse effects as addressed by our original hypothesis.

\section{Studies 3 and 4}

Whereas Studies 1 and 2 explored boredom experienced in discrete achievement episodes (state achievement boredom), Studies 3 and 4 analyzed students' habitual boredom experienced in university settings (trait achievement boredom) and examined their relationships with control, value, achievement behavior, and performance. This combination of studies makes it possible to test the generalizability of the relationships across state and trait constructs of boredom. In addition, whereas the first two studies used subjective indicators of performance, Studies 3 and 4 assessed relationships between boredom and objective academic performance as indicated by students' course grades. Furthermore, drawing on German (Study 3) and North American (Study 4) student samples, we considered the generalizability of the relationships across two different cultural contexts.

\section{Method}

Participants and procedure. In Study 3, 122 students (92 female and 30 male; mean age $=23.43$ years, $S D=3.54$ ) volunteered from undergraduate psychology and education courses at a German university. In Study 4, the sample consisted of 389 students (234 female and 155 male; mean age $=20.63$ years; 
$S D=3.48)$ from undergraduate psychology courses at a midwestern Canadian university who participated in return for extra course credit. Participants completed the measures in one session.

\section{Measures.}

Boredom. We used the trait version of the Learning-Related Boredom scale of Pekrun et al.'s (2002) Achievement Emotions Questionnaire (AEQ) that was administered in Study 2 to assess the boredom participants experienced when studying for their university courses. The German (Titz, 2001) and English (Pekrun et al., 2005) versions of the scale were used in Studies 3 and 4, respectively. The instructions for this measure require respondents to describe how they feel, typically, when studying for their courses. The scale contains 11 items (e.g., "Studying for my courses bores me"; "The material bores me to death"). Participants responded on a scale ranging from 1 (strongly disagree) to 5 (strongly agree), and the scores were summed to form the boredom index ( $\alpha s=.90$ and .92 in Studies 3 and 4, respectively).

Control and value. The German (Titz, 2001) and English (Perry, Hladkyj, Pekrun, \& Pelletier, 2001) versions of Perry's Perceived Academic Control Scale were used to measure achievement-related subjective control. The scale consists of eight items related to influencing academic performance (e.g., "I have a great deal of control over my academic performance in my courses"; "The more effort I put in my courses, the better I do in them"). In Study 3, subjective value was assessed with the five-item trait version of the Academic Value Scale used in Study 2 (e.g., "Studying for my courses is of great personal relevance for me"; "Dealing with the material of my courses is not one of my favorite activities" [reverse scored]). In Study 4, we administered the four-item Task Value scale of the Motivated Strategies for Learning Questionnaire (MSLQ; Pintrich et al., 1991; e.g., "Understanding the subject matter of courses at university is very important to me"; "I am very interested in the content areas of courses at university"). Participants responded on a scale ranging from 1 (strongly disagree) to 5 (strongly agree), and the scores were summed to form the control and value indexes $(\alpha \mathrm{s}=.77$ and .81 for control and .80 and .69 for value in Studies 3 and 4, respectively).

Attention problems, intrinsic motivation, effort, elaboration, rehearsal, and self-regulated learning. Attention problems were assessed by the trait version of the Attention Problems scale of the Learning Strategies Questionnaire that was used in Study 2 (Wild \& Schiefele, 1994; Study 3 only). The scale refers to lack of concentration, distractibility, and task-irrelevant thinking (six items; e.g., "At learning, I lack concentration"; "When studying, I am easily distractible"; "When studying, I notice that my thoughts are elsewhere"; 1 = strongly disagree, $5=$ strongly agree $; \alpha=$ .93). Intrinsic motivation was measured with the German and English trait versions of the Intrinsic Motivation Scale used in Study 2 (Titz, 2001). The scale assesses motivation based on enjoyment of, and interest in, studying academic material (three items; e.g., "I am motivated to study for my courses because I am interested in the material"; 1 = strongly disagree, 5 = strongly agree; $\alpha \mathrm{S}=.79$ and .69 in Studies 3 and 4, respectively).

In Study 3, we used the trait versions of the scales of the Learning Strategies Questionnaire (Wild \& Schiefele, 1994) that were used in Study 2 to assess effort (eight items), elaboration (six items), and rehearsal (seven items). As noted, the German Learning Strategies Questionnaire is based on the MSLQ (Pintrich et al.,
1991). In Study 4, we used the original MSLQ scales for effort (four items), elaboration (six items), and rehearsal (four items). Sample items for both the German and English versions of the scales for effort, elaboration, and rehearsal, respectively, were as follows: "I work hard to do well in my classes even if I don't like what we are doing"; "When reading for my classes, I try to relate the material to what I already know"; and "When studying for my classes, I practice saying the material to myself over and over." Participants responded using a scale ranging from 1 (strongly disagree) to 5 (strongly agree), and the scores were summed to form the effort, elaboration, and rehearsal indexes ( $\alpha s=.79$ and .62 for effort, .82 and .74 for elaboration, and .73 and .59 for rehearsal in Studies 3 and 4, respectively).

In Study 3, we assessed self-regulated learning with the original seven-item German version of the Perceived Self-Regulation at Learning Scale (Titz, 2001) that was used in Study 2. In Study 4, we used a short four-item English version of this scale. The scale items measure students' perceived self-regulation of learning goals, use of strategies, and monitoring of learning outcomes (e.g., "When studying, I set my own goals that I want to attain"; "When studying difficult material, I decide for myself which strategy to use"; "I am able to evaluate for myself how I make progress at learning"). Participants responded by using a scale ranging from 1 (strongly disagree) to 5 (strongly agree), and the scores were summed to form the self-regulation indexes $(\alpha \mathrm{s}=.79$ and .72 in Studies 3 and 4, respectively).

Academic performance. In Study 3, we measured performance by assessing the GPA students had attained at their midstudies exams. At German universities, these exams take place after the second academic year of undergraduate studies. German grades range from 1 to 6 , with 1 indicating high achievement and 6 indicating low achievement. Scores were reversed such that low values indicate low achievement and high values indicate high achievement. In Study 4, performance was measured by assessing students' GPA attained over the academic year prior to the study.

\section{Results and Discussion}

Preliminary analysis. Table 3 displays the descriptive statistics for each of the variables in Studies 3 and 4. We also analyzed descriptive statistics separately by gender. Comparisons were significant for three variables in Study 4. Mean scores for value, elaboration, and rehearsal were higher for female than for male students in this study $(M \mathrm{~s}=15.47$ and $14.78, S D \mathrm{~s}=2.45$ and 2.19 , for value in female and male students, respectively; $t(387)=$ $2.78, p<.01 ; M \mathrm{~s}=22.50$ and $21.34, S D \mathrm{~s}=3.53$ and 3.84 , for elaboration; $t(387)=3.02, p<.01$; and $M \mathrm{~s}=14.29$ and 13.17, $S D s=2.68$ and 2.70, for rehearsal, $t(387)=3.96, p<.01)$. As in Study 2, effect sizes for gender differences were small $(d \mathrm{~s}=.21$, .23 , and .29 for value, elaboration, and rehearsal, respectively; Cohen, 1988). Furthermore, gender differences were not significant for any of these three variables or for any other variables in Study 3.

Relationships of control and value with boredom. We analyzed relationships between the study variables using Pearson product-moment correlations (Table 3 ). In line with Hypothesis 1, academic control correlated significantly negatively with boredom in both German and Canadian students. Similarly, the correlations 
Table 3

Pearson Product-Moment Correlations and Descriptive Statistics for Studies 3 and 4

\begin{tabular}{|c|c|c|c|c|c|c|c|c|c|c|}
\hline Variable & 1 & 2 & 3 & 4 & 5 & 6 & 7 & 8 & 9 & 10 \\
\hline \multicolumn{11}{|l|}{ 1. Boredom } \\
\hline \\
\hline S3 & $-.30^{* *}$ & & & & & & & & & \\
\hline \multirow{2}{*}{\multicolumn{11}{|c|}{ 3. Value }} \\
\hline & & & & & & & & & & \\
\hline $\begin{array}{l}\text { S3 } \\
\text { S4 }\end{array}$ & $\begin{array}{l}-.60^{* *} \\
-.38^{* *}\end{array}$ & $\begin{array}{l}.25 \\
.46^{* *}\end{array}$ & & & & & & & & \\
\hline \multicolumn{11}{|c|}{ 4. Attention problems" } \\
\hline S3 & $.77^{* * *}$ & $-.20^{*}$ & $-.51^{* *}$ & & & & & & & \\
\hline \multicolumn{11}{|c|}{ 5. Intrinsic motivation } \\
\hline S3 & $-.43^{* *}$ & $.21^{*}$ & $.68^{* *}$ & -.14 & & & & & & \\
\hline $\mathrm{S} 4$ & $-.26^{* *}$ & $.31^{* *}$ & $.51^{* *}$ & & & & & & & \\
\hline \multicolumn{8}{|l|}{ 6. Effort } & & & \\
\hline $\begin{array}{l}\text { S3 } \\
\text { S4 }\end{array}$ & $\begin{array}{l}-.51^{*} \\
-.48^{* *}\end{array}$ & $\begin{array}{l}.25 \\
.35^{* *}\end{array}$ & $\begin{array}{l}.44 \\
.38^{* * *}\end{array}$ & & $.32^{* * *}$ & & & & & \\
\hline \multicolumn{11}{|l|}{ 7. Elaboration } \\
\hline S3 & $-.26^{* *}$ & $.20^{*}$ & $.33^{* *}$ & $-.22^{*}$ & $.53^{* * *}$ & $.22^{*}$ & & & & \\
\hline S4 & $-.26^{* *}$ & $.43^{* *}$ & $.52^{* * *}$ & & $.53^{* *}$ & $.40^{* * *}$ & & & & \\
\hline \multicolumn{11}{|l|}{ 8. Rehearsal } \\
\hline $\begin{array}{l}\text { S3 } \\
\text { S4 }\end{array}$ & .01 & -.06 & $\begin{array}{l}.01 \\
31^{* * *}\end{array}$ & .04 & -.05 & $\begin{array}{l}.37^{* * *} \\
28^{* * *}\end{array}$ & $\begin{array}{l}-.10 \\
46^{*+*}\end{array}$ & & & \\
\hline \multicolumn{11}{|l|}{ 9. Self-regulation } \\
\hline S3 & $-.22^{*}$ & $.30^{n+*}$ & $.22^{* *}$ & -.26 & $.43^{*-1}$ & $.36^{\text {t:k }}$ & $.54^{* * *}$ & .14 & & \\
\hline S4 & $-.28^{\text {*itit }}$ & $.48^{\text {t.t. }}$ & $.40^{* *}$ & & $.40^{* *}$ & $.53^{\text {titith }}$ & $.57^{*+*}$ & $.39^{* *}$ & & \\
\hline \multicolumn{11}{|c|}{ 10. Academic performance } \\
\hline S3 & $-.32^{* * * *}$ & $.51^{*+4+4}$ & .22 & -.24 & $.35^{*+4}$ & $.34^{*}$ & .21 & -.18 & $.35^{*}$ & \\
\hline S4 & $-.24^{* m+k}$ & $.27^{* w}$ & $.26^{\prime \prime}$ & & $.20^{* *}$ & $.30^{* * * *}$ & $.37^{* * *}$ & $.14^{*}$ & $.34^{* *}$ & \\
\hline \multicolumn{11}{|l|}{$M$} \\
\hline S3 & 28.34 & 31.00 & 18.25 & 18.13 & 11.07 & 27.93 & 20.44 & 21.88 & 24.25 & 3.88 \\
\hline S4 & 30.69 & 33.39 & 15.16 & & 13.68 & 14.18 & 21.97 & 13.85 & 14.06 & 72.32 \\
\hline \multicolumn{11}{|l|}{$S D$} \\
\hline S3 & 7.92 & 3.97 & 3.67 & 4.43 & 2.28 & 4.86 & 4.31 & 4.77 & 3.67 & 0.73 \\
\hline S4 & 9.28 & 4.76 & 2.38 & & 2.44 & 2.77 & 3.72 & 2.72 & 2.62 & 11.01 \\
\hline \multicolumn{11}{|l|}{ Possible range } \\
\hline S3 & $11-55$ & $8-40$ & $8-25$ & $6-30$ & $3-15$ & $8-40$ & $6-30$ & $7-35$ & $7-35$ & $1-6$ \\
\hline S4 & $11-55$ & $8-40$ & $4-20$ & & $4-20$ & $4-20$ & $6-30$ & $4-20$ & $4-20$ & $1-100$ \\
\hline \multicolumn{11}{|l|}{ Observed range } \\
\hline S3 & $12-47$ & 19-39 & $8-25$ & $8-30$ & $5-15$ & $13-39$ & $11-30$ & $10-34$ & $12-34$ & $2.3-6.0$ \\
\hline S4 & $11-50$ & $12-40$ & $8-20$ & & $8-20$ & $6-20$ & $12-30$ & $6-20$ & $4-20$ & $44-96$ \\
\hline
\end{tabular}

Note. $\quad \mathrm{S} 3=$ Study $3 ; \mathrm{S} 4=$ Study 4.

"Attention problems were not considered in Study 4 .

${ }^{*} p<.05 . \quad p<.01$.

for academic value and boredom were negative in both studies. Relationships were consistent across Studies 3 and 4, suggesting that control and value play similar roles in students' boredom in the two cultural contexts under study. Our findings were also consistent with the results of Studies 1 and 2, indicating that relationships of control and value with boredom are similar across state and trait constructs of boredom.

As in Study 2, we tested for curvilinear components in the relationship between control and boredom by performing simultaneous multiple regression analyses including linear and quadratic terms for control. The quadratic terms were computed after centering the variables. In both studies, control had a significant linear effect on boredom (Study 3: $\beta=-.33, p<.001$; Study $4: \beta=$ $-.34, p<.001$ ). In both studies, there were no significant effects for the quadratic term. Findings thus suggest that the relationship between control and boredom takes linear rather than quadratic forms in both cultural contexts, in line with our hypothesis and with the findings of Study 2.

Relationships of boredom with achievement behavior and performance. Consistent with Hypothesis 2, the correlation between boredom and attention problems during learning was positive (Table 3), thus lending further credibility to the notion that boredom reduces the cognitive resources available for task purposes. Furthermore, in accordance with our hypothesis, boredom correlated negatively with students' intrinsic motivation to learn, effort at studying, elaboration of learning material, and perceived self-regulation of learning in both Studies 3 and 4 . The correlations with rehearsal strategies, however, were nonsignificant in the two studies, in contrast to our hypothesis that boredom would reduce the use of any cognitive learning strategies. As noted earlier, a possible reason is that negative effects of boredom on the use of rehearsal were counterbalanced by positive effects of rehearsal on 
boredom, thus explaining overall zero correlations between the two variables.

With the single exception of the absence of a boredom-rehearsal correlation, the pattern of relationships was consistent with the proposition that boredom is detrimental to attention and engagement in achievement settings. Finally, in line with negative relationships to variables of learning and in accord with Hypothesis 3, boredom also correlated negatively with students' academic performance. Again, all of these relationships proved to be fully consistent across Studies 3 and 4, and with the findings of Studies 1 and 2, suggesting that the relations of boredom with behavior and performance are generalizable across cultural contexts and across state and trait constructs of boredom.

\section{Conclusions}

The findings of Studies 3 and 4 corroborate the postulated relationships of boredom with control, value, achievement behavior, and performance, the nonsignificant relation between boredom and rehearsal being an exception. Achievement-related control, as well as achievement-related value, related negatively to boredom. Relations of control with boredom again proved to be linear rather than curvilinear. In turn, boredom related positively to attention problems, in line with our hypothesis that boredom reduces the availability of cognitive resources by decreasing task-focused concentration and increasing distractibility as well as task-irrelevant thinking. Furthermore, boredom related negatively to intrinsic motivation to learn, study effort, use of elaboration strategies, perceived self-regulation of learning, and academic performance scores, in line with the hypothesis that boredom undermines motivational engagement and cognitive performance. The consistency of findings across studies suggests that they can be generalized across cultural contexts and across state and trait constructs of boredom.

\section{Study 5}

Study 5 used a predictive design to assess the relationships between achievement-related boredom, control-value antecedents, and an objective performance outcome during a two-semester course spanning an entire academic year. A clear temporal ordering of academic control and value (Time 1 assessment), boredom (Time 2 assessment), and ensuing academic performance (Time 3 assessment) was used to disentangle these relationships, while controlling for prior achievement in terms of final high school grades. A situationally specific approach was employed by analyzing students' boredom experienced in a specific course at university, rather than across courses more generally (Goetz et al., 2007).

\section{Method}

Participants and procedure. A total of 287 first-year students (175 female, 112 male) enrolled in an introductory psychology course at a midwestern Canadian university participated in the study in return for extra course credit (mean age: $M=19.75$ years; $S D=3.97$ ). The course extended over two semesters (26 weeks). Participants completed the self-report measures at the beginning of the academic year (Time 1) and later during that year (Time 2).
The Time 1 session assessed academic control and value, as well as demographic variables, four weeks into the year. The Time 2 session took place four months later and assessed course-related boredom. High school grades and end-of-year course grades were obtained from university records at the end of the academic year.

Participation in the Time 2 assessment was reduced to $n=211$, owing to some students' having completed their research participation requirements early in the semester. Attrition analyses using pairwise $t$ tests revealed that scores for students who did participate, and those who did not, did not differ on any of the measures of the Time 1 assessment, including academic control, $t(286)=$ $0.64, p>.05$, and value, $t(286)=-0.31, p>.05$. Attrition also occurred with Time 3 final course grades that were available for $n=269$ students. Attrition analyses using pairwise $t$ tests indicated that scores for students having and those not having Time 3 data did not differ on any of the measures of the Time 1 and 2 assessments, including academic control, $t(286)=-0.33, p>.05$; value, $t(286)=-0.12, p>.05$; and boredom, $t(210)=-0.77$, $p>.05$.

\section{Measures.}

Boredom. To assess participants' boredom in the course at Time 2, we employed a short, six-item version of the LearningRelated Boredom scale of Pekrun et al.'s (2002) Achievement Emotions Questionnaire (AEQ) used in Studies 2 through 4. The instructions for the measure required respondents to describe how they felt when studying for the course. Participants responded on a scale ranging from 1 (strongly disagree) to 5 (strongly agree),, and the scores were summed to form the boredom index $(\alpha=.91)$.

Control and value. Academic control and academic value were assessed as part of the Time 1 assessment. We measured academic control with the eight-item Perceived Academic Control Scale (Perry et al., 2001) that was used in Studies 3 and 4. Participants responded on a scale ranging from 1 (strongly disagree) to 5 (strongly agree), and the scores were summed to form the control index $(\alpha=80)$. A two-item scale assessing intrinsic value and attainment value was used to determine the overall academic value of the course (items consisted of the following: "I am interested in the study of psychology"; "It is extremely important for me to do well in my psychology course"). Participants responded on a scale ranging from 1 (not at all) to 10 (very much so), and the scores were summed to form the value index $(\alpha=.66)$.

Academic performance. Final course grades were used to assess academic performance in the course $(1=\mathrm{F}, 2=\mathrm{D}, 3=\mathrm{C}$, $4=\mathrm{C}+, 5=\mathrm{B}, 6=\mathrm{B}+, 7=\mathrm{A}, 8=\mathrm{A}+$ ). As all students were enrolled in their first year of college, we used high school final grades as an indicator of prior academic achievement, defined as the overall average percentage in students' last year of high school.

Data analysis. Structural equation modeling (AMOS 6.0; Arbuckle, 2005) was used to assess relationships between variables over time. Full information maximum likelihood procedures (Byrne, 2001) were employed to compensate for missing data. The raw data served as input, and the solutions were generated on the basis of maximum likelihood estimation. As indicators for performance, the manifest one-item variables of high school final achievement and final course grades were included. For control, value, and boredom, we estimated latent variables. For value, the two single items of the value scale served as indicators. For 
control, four two-item parcels were created, and for boredom, three two-item parcels were created. Before constructing parcels, principal-components analysis was used to analyze the dimensionality of the item sets for control and boredom. The findings corroborated unidimensionality for both item sets, with one factor having an eigenvalue greater than one for each of the two sets (eigenvalues were 3.34 and 4.16 for the Control and Boredom factors, respectively). Correlations between the manifest variables used are presented in the Appendix.

\section{Results and Discussion}

Preliminary analysis. Table 4 presents the descriptive statistics for each of the variables in Study 5. We also analyzed descriptive statistics separately by gender. High school final grades were higher for female than for male students $(M \mathrm{~s}=76.74 \%$ and $72.23 \%, S D \mathrm{~s}=8.17 \%$ and $8.36 \%$, respectively), $t(285)=3.29$, $p<.01$. In addition, compared with male students, female students reported more academic value $(M \mathrm{~s}=16.86$ and $15.38, S D \mathrm{~s}=3.07$ and 4.09 , respectively), $t(285)=3.26, p<.01$, and less boredom $(M \mathrm{~s}=12.93$ and $15.48, S D \mathrm{~s}=5.08$ and 5.77), $t(209)=-3.34$, $p<.01$. Gender differences were not significant for academic control and final course grades. The pattern of differences thus suggests that female students attained better final high school grades, valued the university course more, and experienced less boredom than male students. However, effect sizes for these gender differences were small, with the exception of a medium effect size for high school achievement $(d s=.54, .29$, and -.33 for high school achievement, value, and boredom, respectively; Cohen, 1988). Furthermore, the absence of gender differences for these variables in Studies 2 and 3 implies that they did not generalize across studies.

Relationships of control and value with boredom. We analyzed relationships between the study variables using Pearson product-moment correlations (Table 4). Time 1 achievementrelated academic control and value correlated negatively with Time 2 learning-related boredom, in line with Hypothesis 1 and with the findings of Studies 2, 3, and 4. The correlation between control and value scores was next to zero, implying that the two variables could be regarded as independent predictors of boredom. In contrast to Studies 2, 3, and 4, there was a clear temporal

Table 4

Pearson Product-Moment Correlations and Descriptive Statistics for Study 5

\begin{tabular}{lccccc}
\hline \multicolumn{1}{c}{ Variable } & 1 & 2 & 3 & 4 & 5 \\
\hline $\begin{array}{l}\text { 1. Boredom } \\
\text { 2. Control }\end{array}$ & $-.22^{* *}$ & - & & & \\
3. Value & $-.35^{* *}$ & .06 & - & & \\
4. High school & & & & & \\
$\quad$ achievement & $-.17^{*}$ & .10 & .12 & - & \\
5. Final course & & & & & \\
$\quad$ grade & $-.36^{* *}$ & .06 & $.14^{*}$ & $.48^{* *}$ & - \\
$M$ & 17.15 & 33.94 & 16.34 & 75.27 & 4.73 \\
SD & 6.49 & 4.41 & 4.40 & 8.40 & 1.90 \\
Possible range & $6-30$ & $8-40$ & $2-20$ & $0-100$ & $1-8$ \\
Observed range & $6-30$ & $9-40$ & $2-20$ & $56-94$ & $1-8$ \\
\hline
\end{tabular}

${ }^{*} p<.05 . \quad{ }^{* *} p<.01$. ordering in the present study, and the time lag between the assessment of control and value, on the one hand, and boredom, on the other, was considerable. These findings imply that students' appraisals of control and value are powerful predictors of their boredom experienced later in the academic year.

As in the preceding studies, we tested the control and boredom relationship for linearity by performing a simultaneous multiple regression analysis including linear and quadratic terms for control. The quadratic term was computed after centering the variables. Control had a significant linear effect on boredom $(B=$ $-.27, p<.001)$. There was no significant effect for the quadratic term. This finding suggests that the relationship between control and boredom takes linear rather than quadratic forms, in line with hypotheses and with the findings of Studies 2, 3, and 4.

Relationships of boredom with performance outcomes. Boredom correlated substantially and negatively with final course grades (Table 4), in accordance with our hypothesis that boredom has negative effects on academic performance. ${ }^{6}$ In addition, there was a significant, albeit lower, negative correlation between boredom and students' prior achievement in terms of final high school grades. As seen from a control-value theory perspective, this latter correlation likely was due to the effects of prior achievement on students' subsequent development of academic control and values influencing boredom. Overall, the pattern of time-lagged correlations suggests that boredom can be both an antecedent and an outcome of impaired academic performance.

Structural equation modeling of relationships between control-value antecedents, boredom, and performance outcomes. Structural equation modeling was used to test our hypotheses concerning the relationships between control and value, boredom, and course performance. Specifically, we tested the following three propositions as derived from our original hypotheses (see Figure 1): (1) Control and value are negative predictors of boredom. (2) Because control and value function as proximal antecedents of boredom, any predictive effects of prior achievement on boredom are mediated by these appraisals. (3) Boredom is a negative predictor of subsequent final course performance while controlling for prior achievement.

\footnotetext{
${ }^{6}$ Whereas boredom and lack of interest are conceptually distinct, it remains an open question whether they are independent predictors of performance. To determine whether boredom predicted course performance independently of students' interest in the course, we conducted a supplementary analysis based on a data set that used the same predictive design and was related to the same kind of academic courses as Study 5 , but with a different sample $(N=131$ undergraduate students; 89 female and 42 male). A one-item measure of interest ("I think that what we learn in my introductory psychology course is interesting") and the same boredom scale as used in Study 5 were included in an assessment 4 months after the beginning of the academic year. Course performance was measured by final course grades. Boredom and interest correlated negatively $(r=-.66$, $p<.001$ ), in line with the proposition that boredom and lack of interest are related. In a simultaneous multiple regression analysis, prior achievement and interest were positive predictors of performance $(B=.32, p<.01$, and $\beta=.22, p<.05$, respectively), whereas boredom was a negative predictor $(B=-.33, p<.01)$. This finding corroborates that boredom is a negative predictor of performance independently of the effects of prior achievement and interest.
} 


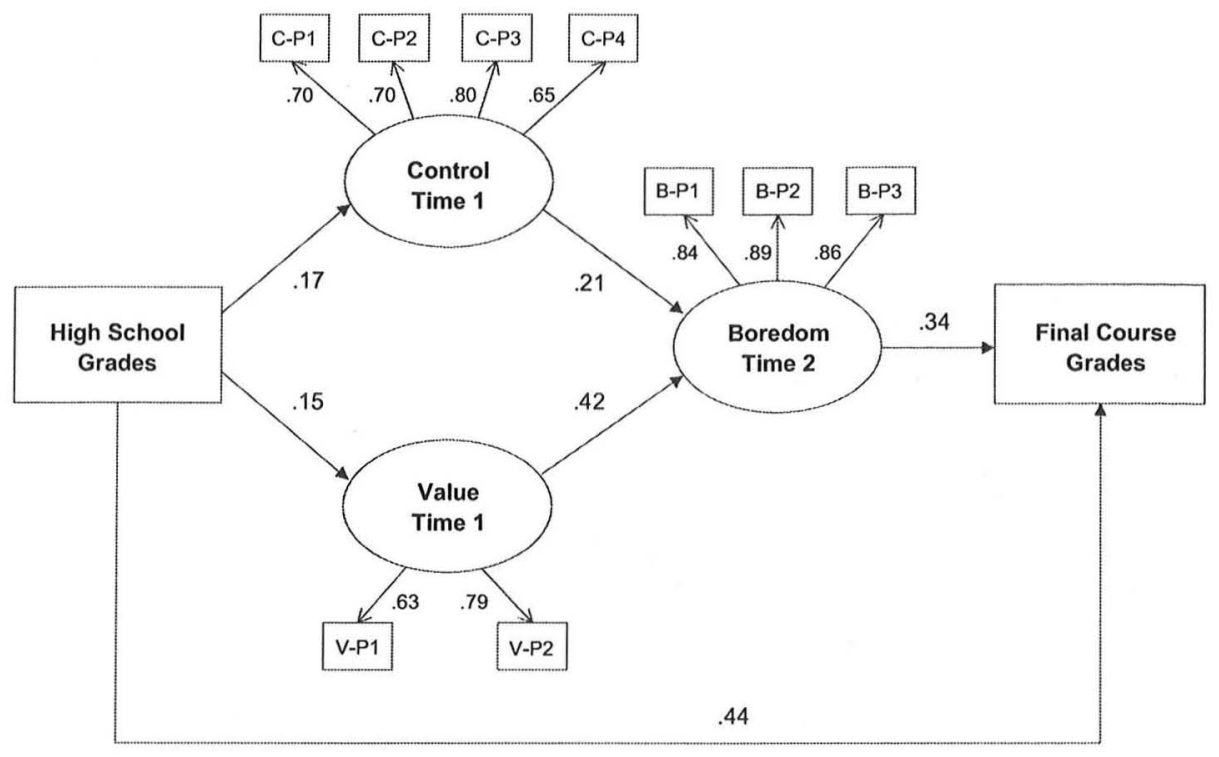

Figure 1. Structural Equation Model 1 for control (C), value (V), boredom (B), and performance. P1, P2, P3, and P4 represent Parcels 1, 2, 3, and 4, respectively.

We constructed a mediational model representing these hypotheses (Model 1) and tested it against a default model including mediational as well as nonmediational effects (Model 2). In the mediational model (Model 1), it was assumed that control and value were negative predictors of boredom, and that boredom was a negative predictor of performance while controlling for high school GPA (see Figure 1). In addition, it was assumed that any links between high school GPA and boredom were mediated by control and value. The corresponding nonmediational default model (Model 2) included the same predictive effects, along with three paths representing the direct effect of high school GPA on boredom and the direct effects of control and value on final course grades.

Testing fit for Models 1 and 2. Following Hoyle and Panter's (1995) recommendations, we used both absolute and incremental fix indexes to evaluate model fit. The results confirmed that the mediational model (Model 1) had an excellent fit to the data. Fit indexes for the model were as follows: $\chi^{2}(40)=54.60, p>.05$; $\chi^{2} / d f$ ratio $=1.36$; comparative fit index $(C F I)=.98$; TuckerLewis index $(T L I)=.97$; and root mean square error of approximation $(R M S E A)=.036$. Given that the chi-square statistic is sensitive to sample sizes greater than 100 (e.g., Lei \& Lomax, 2005), the nonsignificance of this statistic is especially impressive and implies that the model represents the data very well.

Fit indexes for the default model (Model 2) were as follows: $\chi^{2}(37)=50.95, p>.05 ; \chi^{2} / d f$ ratio $=1.37 ; C F I=.98 ; T L I=.97 ;$ and $R M S E A=.036$. The absolute differences of the fit indexes for the mediational and the default model suggest that the more constrained mediational model does not imply any substantial loss of fit, as compared with the default model. In addition, the loss of fit did not reach significance, $\Delta \chi^{2}(3)=3.64, p=.30$. The comparison of the mediational model and the default model thus suggested that the mediational hypotheses underlying Model 1 could be maintained. Furthermore, none of the three additional direct effects that were included in the default model were significant, providing further evidence for the validity of our mediational hypotheses.

Control and value as predictors of boredom. In line with Hypothesis 1, control and value had negative effects on boredom. Furthermore, prior achievement (high school grades) had positive, albeit relatively weak effects on control and value. However, as noted, the direct effect of prior achievement on boredom did not reach significance in the default model. In line with expectations, this pattern of findings suggests that the effects of prior achievement on boredom were mediated by students' control and value appraisals.

Boredom as a predictor of course performance. Prior achievement was a strong positive predictor of final course grades. By implication, any significant predictive effects of additional variables on final course grades can be regarded as substantial evidence for the importance of these variables. In line with our hypotheses, boredom did, in fact, have a considerable incremental effect, adding to the effect of prior achievement and suggesting that boredom has a substantial, negative influence on academic performance.

\section{Conclusions}

Using a predictive design, Study 5 confirmed our hypothesis that subjective control and value negatively predict students' achievement boredom. Furthermore, the findings of mediational structural equation modeling showed that the predictive effect of prior achievement on subsequent boredom was mediated by these appraisal variables. As to the consequences of boredom, findings suggest that boredom has a substantial, deleterious effect on students' course performance, even when controlling for prior achievement. These results are in line with the findings of Studies $1,2,3$, and 4 and extend these findings by showing how appraisals 
predict boredom, and boredom predicts performance, in a temporally ordered sequence of assessments.

\section{General Discussion}

Boredom is pervasive in achievement settings and can have deleterious consequences for motivation, behavior, and performance. Nevertheless, in contrast to other achievement emotions such as test anxiety, there is a conspicuous lack of systematic research on achievement-related boredom, with the exception of studies on the effects of boredom associated with very simple, repetitive tasks (Fisher, 1993). Boredom is a prime example that research on achievement emotions has neglected activity-related emotions, in contrast to outcome emotions such as pride, anxiety, and shame.

In the present research, we analyzed appraisal antecedents and performance effects of achievement boredom. We articulated a set of hypotheses based on Pekrun's (2006) control-value theory of achievement emotions and tested these hypotheses in five studies focusing on boredom occurring in university settings. Studies comprised one qualitative and one quantitative study on boredom experienced within single achievement-related episodes (state achievement boredom), two quantitative studies on students' habitual boredom (trait achievement boredom), and one predictive study on boredom in a university course. Samples consisted of students from both North American and German universities. This set of studies made it possible to test the generalizability of findings across state and trait constructs of boredom, qualitative and quantitative methodologies of assessing boredom, crosssectional and longitudinal designs, and different cultural contexts.

In conceptualizing boredom, we argued that achievementrelated boredom is a negative, deactivating emotion experienced when performing achievement activities. The findings of the qualitative, exploratory Study 1 corroborated that boredom is experienced as an unpleasant, physiologically deactivating state. Additionally, the findings of this study suggested that boredom is experienced quite frequently by students when attending class and studying for their courses, thus confirming assumptions on the pervasiveness of this emotion.

\section{Control-Value Antecedents of Achievement Boredom}

The findings on subjective control and values as antecedents of achievement boredom were in line with expectations. The results from the five studies showed that both control appraisals and value appraisals pertaining to achievement activities related negatively to students' boredom. The consistency of the results is impressive, as these negative relationships were found, without a single exception, across all five studies. Findings thus imply generalizability across different constructs (state vs. trait achievement boredom), methodologies (qualitative, cross-sectional, and predictive), and cultural contexts. These uniformly negative relationships indicate that perceived lack of control over achievement activities and lack of valuation of these activities are crucial individual determinants of boredom in academic achievement settings.

With regard to control, Csikszentmihalyi (1975) posited that boredom is induced by high-control conditions, as defined by a combination of high capabilities and low task demands, which would imply a positive relationship between perceived control and boredom. This proposition is likely valid for achievement settings involving simple routine tasks, such as monotonous assembly line or monitoring work (Fisher, 1993). However, the present results suggest that it is not well suited to explaining the boredom experienced by students in academic settings. Rather, students' boredom seems to be characterized by negative, rather than positive, relations with control.

The present findings also are in line with our hypothesis that functional relationships between control and boredom should take linear forms in an academic context, in contrast to relationships between control and boredom more generally, which may well be curvilinear (with both very low and very high levels of control contributing to boredom). We did not find any evidence for curvilinearity of control-boredom relationships. Rather, these relationships proved to be linear in all of the four quantitative studies. Most likely, the academic setting of university courses is complex and challenging for students. Consequently, very high levels of control inducing boredom are likely never reached by most students when attending university courses or studying related learning material, highly gifted students being a possible, rare exception.

\section{Links of Achievement Boredom With Behavior and Performance}

We expected that boredom would cause attention problems in terms of lack of concentration, distractibility, and task-irrelevant thinking; reduce intrinsic motivation and effort; lead to shallow information processing and an underuse of cognitive strategies such as elaboration and rehearsal; and impair self-regulation of learning. Consequently, we expected that boredom would have universally negative effects on academic performance.

Consistent with these hypotheses, boredom related uniformly positively to attention problems and negatively to intrinsic motivation, effort, and self-regulation across studies. The pattern of results was less consistent for the use of elaboration and rehearsal strategies. In Studies 3 and 4, students' habitual boredom related negatively to elaboration, in line with expectations. In Study 2 analyzing situational boredom within single episodes of learning, however, boredom and use of elaboration were unrelated. Furthermore, unexpectedly, boredom and rehearsal did not relate significantly in Studies 3 and 4, and even related weakly positively in Study 2. As noted earlier, zero or slightly positive correlations between boredom and rehearsal may be due to reciprocal causation, including positive effects of rehearsal on boredom and negative effects of boredom on use of rehearsal, thus amounting to negative feedback loops producing weak overall relationships.

In line with negative links of boredom with attention, motivation, effort, and (most likely) use of cognitively flexible strategies such as elaboration, boredom also related negatively to variables of academic performance across all five studies. Most importantly, in Study 5 , boredom had a negative predictive effect on academic performance in terms of students' final course grades that was substantial $(-34)$ even when controlling for prior achievement. Findings thus confirm hypotheses on the deleterious consequences of boredom for performance in demanding achievement settings. 


\section{Limitations and Suggestions for Future Research}

The five studies reported here analyzed achievement boredom as experienced by students in university settings. On a theoretical level, we believe that our propositions on this emotion are generalizable to any age group and achievement setting involving complex and difficult tasks (Pekrun, 2009). Empirically, however, it is open to question whether the present pattern of findings will, in fact, be replicable for different age groups, such as kindergarten through 12th-grade students, and for other kinds of achievement contexts.

Furthermore, our studies were conducted in field settings and used nonexperimental designs. Although this strategy can ensure ecological validity of findings, it does not provide the rigor of testing causal hypotheses that is provided by experiments. Future studies should complement the approach taken here by assessing boredom after experimentally manipulating control and value, and by assessing performance on academic tasks after experimentally manipulating participants' boredom. Furthermore, measurement of boredom in the present research relied on self-report assessment. Whereas self-report seems to be the best method available for assessing achievement emotions (see, e.g., Zeidner, 1998), future studies should also utilize alternative methods, such as neuroimaging, physiological measurement, and analysis of facial and postural expression of boredom.

Another important task for future research is to analyze the linkages of boredom with other achievement emotions. In our own studies, we found that students' boredom correlated positively with anger and hopelessness in achievement situations (Goetz et al., 2007; Pekrun et al., 2005; Titz, 2001). Conceivably, these two emotions may be aroused when prolonged boredom is experienced. Anger may be triggered when escape from boredom is not possible because attending school is compulsory, and hopelessness may emerge when boredom contributes to feelings that any attempts to control academic performance will fail. Empirically, such sequential and causal relations between boredom and other achievement emotions have yet to be identified.

Finally, it should be noted that achievement emotions, their antecedents, and their outcomes can be linked by reciprocal causation over time (Pekrun, 2006). Specifically, academic success and failure likely constitute an important determinant of students' perceptions of control and values, thereby influencing the emotions shaped by these appraisals and suggesting that boredom and performance can reciprocally influence each other. In Study 5 of the present research, reciprocal relations were taken into account by including achievement variables both as an antecedent and as an outcome of boredom. Specifically, prior achievement was controlled when estimating the predictive effects of boredom on course performance, thus minimizing the likelihood that the influence of boredom was a mere epiphenomenon of prior achievement. However, to fully disentangle reciprocal relations, multiple assessments would be needed for appraisals and boredom as well. As such, subsequent research should systematically address reciprocal links among all three constructs over time.

\section{Implications for Educational Practice}

The findings of the present research have a number of implications for practice. Whereas it may be speculated that boredom can have beneficial effects in some individuals under specific circumstances (Vodanovich, 2003), the evidence in our studies suggests that boredom typically impairs attention, motivation, behavioral strategies, and performance in achievement settings. The pervasiveness of the boredom experienced by many students, coupled with its deleterious effects, clearly implies that educators, administrators, and policy makers responsible for the design of academic settings should pay more attention to this emotion.

With regard to the prevention or reduction of boredom, the present findings suggest that specific measures could focus on increasing the perceived values of activities in achievement settings (e.g., by promoting students' interest in academic material; Hidi \& Renninger, 2006; Hulleman \& Harackiewicz, 2009). Moreover, it would be important to provide a sufficient match between task demands and individual competencies, such that achievementrelated control can be experienced. However, a perfect match would require tasks that are cognitively challenging for all students, but that do not exceed any individual student's capabilities. Given that some degree of mismatch inevitably occurs in the classroom, it may be helpful to promote students' competencies to modify tasks and self-regulate approaches to learning, thus enabling them to restore the balance of demands and individual capabilities in self-directed ways (Rohrkemper \& Corno, 1988; also see Nett, Goetz, \& Hall, 2010; Sansone, Weir, Harpster, \& Morgan, 1992).

Beyond issues of instructional design, some students may suffer from a boredom-inducing lack of control due to subjective underestimation of their own abilities. For these students, directly modifying their control appraisals may prove helpful. One way of doing so involves cognitive treatment (Zeidner, 1998), such as attributional retraining targeted at changing individual control cognitions (Ruthig, Perry, Hall, \& Hladkyj, 2004). Even if such measures are taken, however, it seems likely that boredom cannot always be prevented. Therefore, helping students to regulate their boredom and to cope with this emotion may prove to be an additional effective measure.

By necessity, given the paucity of empirical research, any considerations regarding implications for educational practice are speculative to date and in need of empirical validation. Intervention programs targeting achievement boredom in education, or any other kind of achievement context, are still largely lacking. Given the deleterious effects of this emotion, there is a clear need to develop, implement, and evaluate programs that aim to prevent or reduce the boredom that, according to our findings, is so frequently experienced by students in achievement settings.

\section{References}

Acee, T. W., Kim, H., Kim, H. J., Kim, J., Hsiang-Ning, R. C., Kim, M., Cho, Y., Wicker, F. W., \& The Boredom Research Group (2010). Academic boredom in under- and overchallenging situations. Contemporary Educational Psychology, 35, 17-27. doi: 10.1016/j.cedpsych .2009 .08 .002

Amos, A., Wiltshire, S., Haw, S., \& McNeill, A. (2006). Ambivalence and uncertainty: Experiences of and attitudes toward addiction and smoking cessation in the mid-to-late teens. Health Education Research, 21, 181191. doi:10.1093/her/cyh054

Anshel, M. H. (1991). A survey of elite athletes on the perceived causes of using banned drugs in sport. Journal of Sport Behavior, 14, 283-310. 
Arbuckle, J. L. (2005). AMOS 6.0 [Computer software]. Springhouse, PA: AMOS Development.

Bearden, L., Spencer, W., \& Moracco, J. (1989). A study of high school dropouts. School Counselor, 37, 113-120.

Berlyne, D. E. (1960). Conflict, arousal, and curiosity. New York: McGraw-Hill.

Blaszcsynski, A., McConaghy, N., \& Frankova, A. (1990). Boredom proneness in psychopathological gambling. Psychological Reports, 67, $35-42$.

Byrne, B. M. (2001). Structural equation modeling with AMOS: Basic concepts, applications, and programming. Mahwah, NJ: Erlbaum.

Cantor, G. N. (1968). Effects of a "boredom" treatment on children's simple RT performance. Psychonomic Science, 10, 299-300.

Cohen, J. (1988). Statistical power analysis for the behavioral sciences. Hillsdale, NJ: Erlbaum.

Coury, B. G., \& Drury, C. G. (1986). The effects of pacing on complex decision-making inspection performance. Ergonomics, 29, 489-508.

Csikszentmihalyi, M. (1975). Beyond boredom and anxiety. San Francisco, CA: Jossey-Bass.

Daniels, L. M., Stupnisky, R. H., Pekrun, R., Haynes, T. L., Perry, R. P., \& Newall, N. E. (2009). A longitudinal analysis of achievement goals: From affective antecedents to emotional effects and achievement outcomes. Journal of Educational Psychology, 101, 948-963. doi:10.1037/ a0016096

Dicintio, M. J., \& Gee, S. (1999). Control is the key: Unlocking the motivation of at-risks students. Psychology in the Schools, 36, 231-237.

Duda, J. L., Fox, K. R., Biddle, S. J., \& Armstrong, N. (1992). Children's achievement goals and beliefs about success in sport. British Journal of Educational Psychology, 62, 313-323.

Eccles, J. S. (2005). Subjective task value and the Eccles et al. model of achievement-related choices. In A. J. Elliot \& C. Dweck (Eds.), Handbook of competence and motivation (pp. 105-121). New York: Guilford Press.

Elliot, A. J., \& Dweck, C. (Eds.). (2005). Handbook of competence and motivation. New York: Guilford Press.

Farmer, R., \& Sundberg, N. D. (1986). Boredom proneness-The development and correlates of a new scale. Journal of Personality Assessment, 50, 4-17.

Fenichel, O. (1934). Zur Psychologie der Langeweile [On the psychology of boredom]. Imago, 20, 270-281.

Fisher, C. D. (1993). Boredom at work: A neglected concept. Human Relations, 46, 395-417.

Fogelman, K. (1976). Bored eleven-year-olds. British Journal of Social Work, 6, 201-211.

Folkman, S., \& Lazarus, R. S. (1985). If it changes it must be a process: Study of emotion and coping during three stages of a college examination. Journal of Personality and Social Psychology, 48, 150-170.

Fredrickson, B. L. (2001). The role of positive emotions in positive psychology: The broaden-and-build theory of positive emotions. American Psychologist, 56, 218-226.

Gigy, L. K., \& Kelly, J. B. (1992). Reasons for divorce: Perspectives of divorcing men and women. Journal of Divorce and Remarriage, 18 , 169-187.

Gjesme, T. (1977). General satisfaction and boredom at school as a function of pupils' personality characteristics. Scandinavian Journal of Educational Research, 21, 113-146.

Goetz, T., \& Frenzel, A. C. (2006). Phänomenologie schulischer Langeweile [Phenomenology of academic boredom]. Zeitschrift für Entwicklungspsychologie und Pädagogische Psychologie, 38, 149-153.

Goetz, T., Frenzel, A. C., Pekrun, R., Hall, N. C., \& Lüdtke, O. (2007). Between- and within-domain relations of students' academic emotions Journal of Educational Psychology, 99, 715-733. doi:10.1037/00220663.99.4.715

Goetz, T., Pekrun, R., Hall, N., \& Haag, L. (2006). Academic emotions from a social-cognitive perspective: Antecedents and domain specificity of students' affect in the context of Latin instruction. British Journal of Educational Psychology, 76, 289-308. doi:10.1348/000709905X42860

Guinn, R. (1975). Characteristics of drug use among Mexican-American students. Journal of Drug Education, 5, 235-241.

Hamilton, J. A., Haier, R. J., \& Buchsbaum, M. S. (1984). Intrinsic enjoyment and boredom coping scales: Validation with personality, evoked potential, and attention measures. Personality and Individual Differences, 5, 183-193.

Harackiewicz, J. M., Durik, A. M., Barron, K. E., Linnenbrink-Garcia, L., \& Tauer, J. M. (2008). The role of achievement goals in the development of interest: Reciprocal relations between achievement goals, interest, and performance. Journal of Educational Psychology, 100, 105-122. doi: 10.1037/0022-0663.100.1.105

Harris, M. B. (2000). Correlates and characteristics of boredom proneness and boredom. Journal of Applied Social Psychology, 30, 576-598.

Hembree, R. (1988). Correlates, causes, effects, and treatment of test anxiety. Review of Educational Research, 58, 47-77.

Hidi, S. (2006). Interest: A unique motivational variable. Educational Research Review, $1,69-82$.

Hidi, S., \& Renninger, A. (2006). The four-phase model of interest development. Educational Psychologist, 41, 111-127.

Ho, R. (1989). Why do people smoke? Motives for maintenance of smoking behavior and its possible cessation. Australian Psychologist, 24, $385-400$.

Hoyle, R., \& Panter, A. (1995). Writing about structural equation models. In R. Hoyle (Ed.), Structural equation modeling: Concepts, issues, and applications (pp. 100-119). Thousand Oaks, CA: Sage

Hulleman, C. S., Durik, A. M., Schweigert, S. A., \& Harackiewicz, J. M. (2008). Task values, achievement goals, and interest: An integrative analysis. Journal of Educational Psychology, 100, 398-416. doi: 10.1037/0022-0663.100.2.398

Hulleman, C. S., \& Harackiewicz, J. M. (2009). Promoting interest and performance in high school science classes. Science, 326(5958), 14101412. doi: $10.1126 /$ science. 1177067

Jagacinski, C. M., \& Duda, J. L. (2001). A comparative analysis of contemporary achievement goal orientation measures. Educational and Psychological Measurement, 61, 1013-1039.

Jarvis, S., \& Seifert, T. (2002). Work avoidance as a manifestation of hostility, helplessness, and boredom. Alberta Journal of Educational Research, 48, 174-187.

Johnstone, T., \& Scherer, K. R. (2000). Vocal communication of emotion. In M. Lewis \& J. M. Haviland-Jones (Eds.), Handbook of emotions (2nd ed., pp. 220-235). New York: Guilford Press.

Johnstone, T., Scherer, K. R., \& Schorr, A. (Eds.). (2001). Appraisal processes in emotion: Theory, methods, research. New York: Oxford University Press.

Karsten, A. (1928). Psychische Sättigung [Psychic satiation]. Psychologische Forschung, 10, 142-254.

Kass, S. J., Vodanovich, S. J., Stanny, C. J., \& Taylor, T. M. (2001). Watching the clock: Boredom and vigilance performance. Perceptual and Motor Skills, 92, 969-976.

Klapp, O. (1986). Overload and boredom. New York: Greenwood Press.

Kleinginna, P. R., \& Kleinginna, A. M. (1981). A categorized list of emotion definitions, with suggestions for a consensual definition. Motivation and Emotion, 5, 345-379.

Larson, R. W., \& Richards, M. H. (1991). Boredom in the middle school years: Blaming schools versus blaming students. American Journal of Education, 99, 418-443.

Lei, M., \& Lomax, R. G. (2005). The effect of varying degrees of nonnormality in structural equation modeling. Structural Equation Modeling, 12, 1-27.

Lewin, K. (1928). Die Bedeutung der psychischen Sättigung für einige Probleme der Psychotechnik [Significance of psychic saturation for 
some problems in psychotechnics]. Psychotechnische Zeitschrift, 3, 182-188.

Lewis, M., Haviland-Jones, J. M., \& Feldman Barrett, L. (Eds.). (2008) Handbook of emotions (3rd ed.). New York: Guilford Press.

London, H., Schubert, D. S. P., \& Washburn, D. (1972). Increase of autonomic arousal by boredom. Journal of Abnormal Psychology, 80, 20-36.

Maroldo, G. K. (1986). Shyness, boredom, and grade point average among college students. Psychological Reports, 59, 395-398.

Mikulas, W. L., \& Vodanovich, S. J. (1993). The essence of boredom. The Psychological Record, 43, 3-12.

Nett, U. E., Goetz, T., \& Hall, N. (2010). Coping with boredom in school: An experience sampling perspective. Manuscript submitted for publication.

Newberry, A. L., \& Duncan, R. D. (2001). Roles of boredom and life goals in juvenile delinquency. Journal of Applied Social Psychology, 31, 527-541.

Pan, C. S., Shell, R. L., \& Schleifer, L. M. (1994). Performance variability as an indicator of fatigue and boredom effects in a VDT data-entry task. International Journal of Human-Computer Interaction, 6, 37-45.

Pekrun, R. (1988). Emotion, Motivation und Persönlichkeit [Emotion, motivation, and personality]. Munich/Weinheim, Germany: Psychologie Verlags Union.

Pekrun, R. (1992a). Kognition und Emotion in studienbezogenen Lern- und Leistungssituationen: Explorative Analysen [Cognition and emotion in academic achievement settings: An exploratory analysis]. Unterrichtswissenschaft, 20, 308-324.

Pekrun, R. (1992b). The expectancy-value theory of anxiety: Overview and implications. In D. G. Forgays, T. Sosnowski, \& K. Wrzesniewski (Eds.), Anxiety: Recent developments in self-appraisal, psychophysiological and health research (pp. 23-41). Washington, DC: Hemisphere.

Pekrun, R. (1992c). The impact of emotions on learning and achievement: Towards a theory of cognitive/motivational mediators. Applied Psychology: An International Review, 41, 359-376.

Pekrun, R. (1993). Facets of students' academic motivation: A longitudinal expectancy-value approach. In M. L. Maehr \& P. R. Pintrich (Eds.) Advances in motivation and achievement (Vol. 8, pp. 139-189). Greenwich, CT: JAI Press.

Pekrun, R. (2000). A social cognitive, control-value theory of achievement emotions. In J. Heckhausen (Ed.), Motivational psychology of human development (pp. 143-163). Oxford, United Kingdom: Elsevier Science.

Pekrun, R. (2006). The control-value theory of achievement emotions: Assumptions, corollaries, and implications for educational research and practice. Educational Psychology Review, 18, 315-341. doi:10.1007/ s10648-006-9029-9

Pekrun, R. (2009). Global and local perspectives on human affect: Implications of the control-value theory of achievement emotions. In $\mathrm{M}$. Wosnitza, S. A. Karabenick, A. Efklides, \& P. Nenniger (Eds.), Contemporary motivation research: From global to local perspectives (pp. 97-115). Toronto, Ontario, Canada: Hogrefe.

Pekrun, R., Elliot, A. J., \& Maier, M. A. (2006). Achievement goals and discrete achievement emotions: A theoretical model and prospective test. Journal of Educational Psychology, 98, 583-597. doi:10.1037/00220663.98.3.583

Pekrun, R., Elliot, A. J., \& Maier, M. A. (2009). Achievement goals and achievement emotions: Testing a model of their joint relations with academic performance. Journal of Educational Psychology, 101, 115135. doi: $10.1037 / \mathrm{a} 0013383$

Pekrun, R., Frenzel, A., Goetz, T., \& Perry, R. P. (2007). The control-value theory of achievement emotions: An integrative approach to emotions in education. In P. A. Schutz \& R. Pekrun (Eds.), Emotion in education (pp. 13-36). San Diego, CA: Academic Press.

Pekrun, R., Goetz, T., \& Perry, R. P. (2005). Achievement Emotions Questionnaire (AEQ): User's manual. Department of Psychology, University of Munich, Munich, Germany.
Pekrun, R, Goetz, T , Titz, W., \& Perry, R. P. (2002). Academic emotions in students' self-regulated learning and achievement: A program of quantitative and qualitative research. Educational Psychologist, 37, 91-106.

Perry, R. P., Hladkyj, S., Pekrun, R. H., \& Pelletier, S. T. (2001). Academic control and action control in college students: A longitudinal field study. Journal of Educational Psychology, 93, 776-789.

Pintrich, P. R., Smith, D. A. F., Garcia, T., \& McKeachie, W. J. (1991). A manual for the use of the Motivated Strategies for Learning Questionnaire (MSLQ) (Tech. Report No. 91-B-004). Board of Regents, University of Michigan, Ann Arbor, MI.

Ragheb, M. G., \& Merydith, S. P. (2001). Development and validation of a multidimensional scale measuring free time boredom. Leisure Studies, 20, 41-59.

Rennert, H., \& Berger, I. (1956). Pädagogische und kinderpsychiatrische Betrachtungen über geistig vorausentwickelte Kinder [Educational and psychiatric observations of children showing precocious intellectual development]. Praxis der Kinderpsychologie und Kinderpsychiatrie, 5, 293-296.

Rohrkemper, M., \& Corno, L. (1988). Success and failure on classroom tasks: Adaptive learning and classroom teaching. The Elementary School Journal, 88, 296-312.

Roseman, W. P. (1975). Boredom at school. British Journal of Educational Psychology, 45, 141-152.

Ruthig, J. C., Perry, R. P., Hall, N. C., \& Hladkyj, S. (2004). Optimism and attributional retraining: Longitudinal effects on academic achievement, test anxiety, and voluntary course withdrawal in college students. Journal of Applied Social Psychology, 34, 709-730.

Sansone, C., \& Thoman, D. B. (2005). Interest as the missing motivator in self-regulation. European Psychologist, 10, 175-186. doi:10.1027/10169040.10.3.175

Sansone, C., Weir, C., Harpster, L., \& Morgan, C. (1992). Once a boring task always a boring task? Interest as a self-regulatory mechanism. Journal of Personality and Social Psychology, 63, 379-390.

Sawin, D. A., \& Scerbo, M. W. (1995). Effects of instruction type and boredom proneness in vigilance: Implications for boredom and workload. Human Factors, 37, 752-765.

Scerbo, M. W. (1998). What's so boring about vigilance? In R. R. Hoffman, M. F. Sherrick, \& J. S. Warm (Eds.), Viewing psychology as a whole: The integrative science of William N. Dember (pp. 145-166). Washington, DC: American Psychological Association.

Scherer, K. R. (2000). Emotions as episodes of subsystems synchronization driven by nonlinear appraisal processes. In M. D. Lewis \& I. Granic (Ed.), Emotion, development, and self-organization (pp. 70-99). Cambridge, United Kingdom: Cambridge University Press.

Schiefele, U., Krapp, A., Wild, K.-P., \& Winteler, A. (1993). Der "Fragebogen zum Studieninteresse" (FSI) [The "Study Interest Questionnaire" (SIQ)]. Diagnostica, 39, 335-351.

Schwarzer, R. (1986). Skalen zur Befindlichkeit und Persönlichkeit [Scales on Well-Being and Personality]. Institute of Psychology, Free University of Berlin, Berlin, Germany.

Sisk, D. A. (1988). The bored and disinterested gifted child: Going through school lockstep. Journal for the Education of the Gifted, 11, 5-18.

Skinner, E. A. (1996). A guide to constructs of control. Journal of Personality and Social Psychology, 71, 549-570.

Sommer, B. (1985). What's different about truants? A comparison study of eighth-graders. Journal of Youth and Adolescence, 14, 411-422.

Spacks, P. M. (1995). Boredom: The literary history of a state of mind. Chicago, IL: University of Chicago Press.

Thackray, R. I. (1981). The stress of boredom and monotony: A consideration of the evidence. Psychosomatic Medicine, 43, 165-176.

Tidwell, R. (1988). Dropouts speak out: Qualitative data on early school departures. Adolescence, 23, 939-954.

Titz, W. (2001). Emotionen von Studierenden in Lernsituationen [Students' emotions during learning]. Münster, Germany: Waxmann.

Turner, J. E., \& Schallert, D. L. (2001). Expectancy-value relationships of 
shame reactions and shame resiliency. Journal of Educational Psychology, 93, 320-329.

Vodanovich, S. J. (2003). On the possible benefits of boredom: A neglected area in personality research. Psychology and Education-An Interdisciplinary Journal, 40, 28-33.

Wallace, J. C., Vodanovich, S. J., \& Restino, B. M. (2003). Predicting cognitive failures from boredom proneness and daytime sleepiness scores: An investigation within military and undergraduate samples. Personality and Individual Differences, 34, 635-644.

Wasson, A. S. (1981). Susceptibility to boredom and deviant behavior at school. Psychological Reports, 48, 901-902.

Watson, D., \& Tellegen, A. (1985). Toward a consensual structure of mood. Psychological Bulletin, 98, 219-235.

Watt, J. D., \& Vodanovich, S. J. (1999). Boredom proneness and psychosocial development. Journal of Psychology: Interdisciplinary and Applied, 133, 303-314.
Weiner, B. (1985). An attributional theory of achievement motivation and emotion. Psychological Review, 92, 548-573.

Wiesner, M., Windle, M., \& Freeman, A. (2005). Work stress, substance use, and depression among young adult workers: An examination of main and moderator effects. Journal of Occupational Health Psychology, 10, 83-96. doi:10.1037/1076-8998.10.2.83

Wild, K.-P., \& Schiefele, U. (1994). Lernstrategien im Studium: Ergebnisse zur Faktorenstruktur und Reliabilität eines neuen Fragebogens [Learning strategies of university students: Factor structure and reliability of a new questionnaire]. Zeitschrift für Differentielle und Diagnostische Psychologie, 15, 185-200.

Zeidner, M. (1998). Test anxiety: The state of the art. New York: Plenum Press.

Zeidner, M. (2007). Test anxiety in educational contexts: Concepts, findings, and future directions. In P. A. Schutz \& R. Pekrun (Eds.), Emotion in education (pp. 165-184). San Diego, CA: Academic Press.

\section{Appendix}

Intercorrelations of Variables for Structural Equation Models 1 and 2 (Study 5)

\begin{tabular}{|c|c|c|c|c|c|c|c|c|c|c|c|}
\hline Variable & 1 & 2 & 3 & 4 & 5 & 6 & 7 & 8 & 9 & 10 & 11 \\
\hline \multicolumn{12}{|l|}{ Boredom } \\
\hline 1. Parcel 1 & - & & & & & & & & & & \\
\hline 2. Parcel 2 & $.76^{* *}$ & - & & & & & & & & & \\
\hline 3. Parcel 3 & $.70^{\wedge 4}$ & $.77^{44}$ & - & & & & & & & & \\
\hline \multicolumn{12}{|l|}{ Control } \\
\hline 4. Parcel 1 & -.11 & -.09 & -.10 & - & & & & & & & \\
\hline 5. Parcel 2 & -.13 & -.11 & $-.15^{\circ}$ & $.47^{* *}$ & - & & & & & & \\
\hline 6. Parcel 3 & $-.24^{* n}$ & $-.23^{* * *}$ & $-.19^{k}$ & $.57^{2+4}$ & $.56^{* *}$ & - & & & & & \\
\hline 7. Parcel 4 & -.10 & -.08 & $-.13^{*}$ & $.48^{* *}$ & $.50^{* *}$ & $.50^{* *}$ & - & & & & \\
\hline \multicolumn{12}{|l|}{ Value } \\
\hline 8. Parcel 1 & $-.33^{* *}$ & $-.27^{* *}$ & $-.35^{+\infty}$ & -.04 & .00 & .02 & -.02 & - & & & \\
\hline 9. Parcel 2 & $-.23^{* *}$ & $-.20^{* *}$ & $-.22^{4+1}$ & .07 & .09 & .11 & .10 & $.50^{* * *}$ & - & & \\
\hline \multicolumn{12}{|l|}{ Academic performance } \\
\hline 10. High school GPA & $-.15^{*}$ & $-.15^{*}$ & $-.17^{*}$ & $.16^{*}$ & .07 & $.22^{* *}$ & -.03 & .09 & $.14^{*}$ & - & \\
\hline 11. Final course grades & $-.35^{w \%}$ & $-.36^{* *}$ & $-.42^{* *}$ & .10 & .06 & $.12^{*}$ & -.04 & $.13^{*}$ & $.13^{*}$ & $.49^{* * *}$ & 一 \\
\hline
\end{tabular}

Note. $\mathrm{GPA}=$ grade point average.

${ }^{*} p<.05 . \quad{ }^{* *} p<.01$. 